\title{
The Puzzling Evolution of the Home Bias, Information Processing and Financial Openness
}

\author{
Jordi Mondria* \\ Thomas $\mathrm{Wu}^{\dagger}$ \\ University of Toronto \\ UC Santa Cruz
}

December $2006^{\ddagger}$

\begin{abstract}
This paper presents a rational expectations model of asset prices with rationally inattentive investors that, unlike previous papers, can explain both the substantial amount of equity wealth invested domestically and the puzzling time series behavior of the home bias - an initial plateau before 1985, then a decrease until 1994 followed by stabilization on another plateau. When there is a financial liberalization, investors exploit past information to predict current asset payoffs. The resulting endogenous local information advantage generates a gradual decrease of the home bias until its steady state. In the long run, the home bias remains large due to the interaction of the optimal attention allocation with the optimal portfolio choice. Using measures for information capacity, informational advantages and financial openness as explanatory variables, we are able to explain at least $46.8 \%$ of the variation of the home bias for 19 developed countries from 1988 until 2004. Our estimates show that both variables are significant, with home bias decreasing with financial openness and increasing with information capacity, as predicted by our model.
\end{abstract}

Keywords: Home Bias, Rational Inattention, Asymmetric Information, Portfolio Choice. JEL Codes: F30, D82, G11.

\footnotetext{
${ }^{*}$ Economics Department. Sidney Smith Hall, Room 4085. E-mail: jordi.mondria@utoronto.ca.

${ }^{\dagger}$ Economics Department, 465 E2 Building, Santa Cruz, CA 95060. E-mail: thomaswu@ucsc.edu.

${ }^{\ddagger}$ We thank Karsten Jeske, Per Krusell, Fernanda Nechio, Ricardo Reis, Hélène Rey, Tamra Schimdt, Chris Sims, Laura Veldkamp, Frank Warnock and Noah Williams for their comments and suggestions. All remaining errors are ours.
} 


\section{Introduction}

The home bias puzzle has been the subject of a good deal of research in the literature on international finance. While some authors have focused on institutional factors, such as capital controls, transaction costs or legal issues, many of the recent studies are stressing the role of asymmetric information. Although all models may explain (some more plausibly than others) the existence of some degree of home bias in international investment behavior, none of them are able to account for the puzzling evolution of the bias through the past two decades. The home bias decreased over a few years from 1985 through 1994, and then remained relatively stable since 1994, as shown by Karolyi and Stulz (2002) and Ahearne, Griever and Warnock (2004). The objective of this paper is to propose an information based model that, unlike the rest of the literature, can explain both the substantial amount of equity wealth invested domestically and the troubling time series behavior of the home bias.

The home bias puzzle was raised by French and Poterba (1991) and Tesar and Werner (1995). They showed that, at the beginning of the 90's, the fraction of stock market wealth invested domestically was around $90 \%$ for the U.S. and Japan and around $80 \%$ for the U.K. Several explanations for this puzzle have been provided by the literature on international finance. In the presence of institutional factors ${ }^{1}$ such as capital controls, transaction costs or legal issues one expects investors to hold most of the assets domestically. However, these theories predict a large decrease in the home bias over the last two decades with the fall of international investment barriers that has not occurred. This predicted drop is due to the speed and depth with which institutional barriers to financial trade have been removed during the 80's, increasing both de jure and de facto financial openness across countries. Recent research analyzes the home bias puzzle using asymmetric information ${ }^{2}$. These models tend to exogenously assume asymmetric information between investors. One of the problems with the models with asymmetric information is that in order to explain the substantial amount of home bias, they need to assume large and implausible information asymmetries. Van

\footnotetext{
${ }^{1}$ Black (1974), Stulz (1981), Tesar and Werner (1995), Ahearne, Griever and Warnock (2001), Cooper and Kaplanis (1994, Kraay et al (2000) and Adler and Dumas (1983) among others.

${ }^{2}$ Coval and Moskowitz (1999), Portes and Rey (2005), Kang and Stulz (1997), Gordon and Bovenberg (1996), Brennan and Cao (1997) and Zhou (1998) among others.
} 
Nieuwerburgh and Veldkamp (2006) solved this problem by letting investors choose what home or foreign information to learn about, before deciding what assets to hold. They assume that domestic investors have an information advantage that makes domestic assets slightly less risky, which leads them to purchase more domestic assets than the world portfolio. Thus, investors optimally decide to process more information about the domestic assets since they are generating more uncertainty in the portfolio. As a consequence, since investors become even better informed about domestic assets, they want to hold more domestic assets and process even more information about these assets. However, in their model, home bias increases the higher is the investors' capacity to process information. Therefore, if we assume that the information processing capacity has increased as a consequence of the technological progress experienced in the past decade, their model predicts that home bias should have increased over time.

The main trouble for all the explanations about home bias, as argued by Karolyi and Stulz (2002), is explaining the apparent plateau in the time path of the US home bias after 1994. Models based on exogenous asymmetric information predict that the home bias should have significantly decreased and kept falling since the massive amount of innovations experienced in telecommunication and information technologies has greatly increased investors' access to information. However, neither a significant drop nor an increase has been observed in the home bias over the last decade. Kho, Stulz and Warnock (2006) found that "the average home bias of US investors towards the 47 countries with the largest equity markets did not fall from 1994 to 2004 when countries are equally weighted".

Unlike all the literature, we propose a theory based on asymmetric information that is able to explain the substantial amount of home bias and account for the puzzling evolution of the home bias over time. We present a noisy rational expectations model with rationally inattentive agents. The basic framework, that builds on Mondria (2006) and Van Nieuwerburgh and Veldkamp (2006), introduces dynamics, persistence in the asset payoffs and takes into account financial openness. We can explain the time series behavior of the home bias - an initial plateau before 1985, then a decrease until 1994 followed by stabilization on another plateau - 
when we use the model to simulate the portfolio choices of a country that is forced to live in financial autarky for a couple of periods before opening up to financial transactions. Investors only process information about domestic assets during financial autarky. After financial markets are liberalized, investors are able to hold foreign assets and benefit from international diversification. However, since the information processed while being in autarky can be used to process information about domestic assets in the current period, investors have an endogenous big advantage in holding and processing information about domestic assets. There is a trade off between large endogenous information advantage in domestic assets and diversification. Investors optimally decide to hold most of their portfolio in domestic assets. They also hold and process information about foreign assets because of diversification purposes, but in a modest way. Over time, the large amounts of information processed in autarky about domestic assets are less helpful to predict current asset payoffs. Investors gradually tilt their portfolio towards foreign assets and there is decrease in the home bias. However, the decline in the home bias is not too large because of the interaction between the optimal attention allocation and the optimal portfolio choice. The better information about domestic assets, the higher is the domestic asset holdings. Furthermore, the higher the demand of domestic assets, the greater is the incentive to process information about domestic assets. Therefore, in steady state, when investors have small asymmetric prior beliefs, investors optimally decide to hold a portfolio with mostly domestic assets.

We test some predictions of our model on a panel data set on home bias for 19 developed countries from 1988 until 2004, using three groups of variables that try to measure the degree of information capacity, the degree of informational advantage and the degree of financial openness in each of these countries. We consider different measures of a country's information capacity: the average circulation (or copies printed) of newspapers published at least four times a week; the number of telephone mainlines; the number of mobile telephone subscribers to a public mobile telephone service using cellular technology; and the number of people with access to the internet. We proxy for how familiarized the domestic agent is with foreign countries using the number of international departures made from their country of usual 
residence to any other country for any purpose other than a remunerated activity in the country visited. Financial openness is included using both de facto and de jure measures. Our baseline specifications are able to explain at least $46.8 \%$ of the variation of the home bias in our data set. Our estimates confirm that home bias decreases with financial openness, and increases with information capacity and with information advantage, as predicted by our model.

The remainder of the paper is organized as follows. In Section 2, there is a description of the setup and the solution in the static model. Section 3 introduces persistent asset payoffs and shows an increase in the home bias explained by the model. Section 4 provides an explanation of the home bias behavior over the last twenty years. Section 5 presents the empirical evidence. Section 6 concludes. The Appendix provides technical derivations and proofs.

\section{The Static Model}

Although the main target of the paper is to discuss the puzzling time path of the home bias, we will first examine the static version of the model as an intermediary step. Since the static model has an analytical solution, it will help us to gain intuition about the model's key mechanisms.

\subsection{Basic Setup}

This model introduces heterogeneity among investors to Mondria (2006) in order to study the interaction of the optimal risk factor choice with the optimal asset holdings of each type of investor. The economy consists of two countries and it is populated by a continuum of investors of measure one. There are two types of investors in the economy: a fraction $\lambda$ of home investors and a fraction $1-\lambda$ of foreign investors. Investors hold three different types of assets: a riskless asset that pays $R$ units of consumption good, a home risky asset and a foreign risky asset.

Home and foreign investors have different prior beliefs about the asset payoffs vector $\tilde{R}$ as in Van Nieuwerburgh and Veldkamp (2006). Investors have an initial advantage in processing 
information about domestic assets. The initial advantage is modeled as a lower variance in the prior beliefs. The two risky assets are independent and normally distributed. The prior beliefs of an investor $i$ about an asset $j$ are given by $\tilde{r}_{i, j} \sim N\left(\bar{r}_{j}, \sigma_{r, j}^{2}\right)$, i.e., the prior beliefs of home investors are $\tilde{r}_{h, h} \sim N\left(\bar{r}_{h}, \sigma_{r, h}^{2}\right)$ and $\tilde{r}_{h, f} \sim N\left(\bar{r}_{f}, \phi \sigma_{r, f}^{2}\right)$ where $\phi \geq 1$ and the prior beliefs of foreign investors are $\tilde{r}_{f, h} \sim N\left(\bar{r}_{h}, \phi \sigma_{r, h}^{2}\right)$ and $\tilde{r}_{f, f} \sim N\left(\bar{r}_{f}, \sigma_{r, f}^{2}\right)$ where $\phi \geq 1$. Let $\bar{R}$ and $\Sigma_{R, h}$ denote the mean vector and the diagonal variance-covariance matrix of the prior beliefs about the asset payoffs of a home investor $\tilde{R}_{h}=\left(\tilde{r}_{h, h}, \tilde{r}_{h, f}\right)^{\prime}$. Let $\bar{R}$ and $\Sigma_{R, f}$ denote the mean vector and the diagonal variance-covariance matrix of the prior beliefs about the asset payoffs of a foreign investor $\tilde{R}_{f}=\left(\tilde{r}_{f, h}, \tilde{r}_{f, f}\right)^{\prime}$. The numeraire in the market is the price of the bond and $\tilde{P}=\left(\tilde{p}_{1}, \tilde{p}_{2}\right)^{\prime}$ is the price vector of the risky assets. The net supply of the risky asset $j$ is given by the realization of a random variable $\tilde{z}_{j} \sim N\left(\bar{z}_{j}, \sigma_{z, j}^{2}\right)$. Let $\bar{Z}$ and $\Sigma_{Z}$ denote the mean vector and the diagonal covariance matrix of the vector of net supply $\tilde{Z}=\left(\tilde{z}_{1}, \tilde{z}_{2}\right)^{\prime}$. This randomness can be viewed as the result of some trade of a nonspeculative nature (liquidity traders) or some trade from agents lacking perfect knowledge of the market structure (irrational traders). Asset supply randomness is necessary in order to avoid perfect revelation of private information through the price.

This is a static model in which investors live for four periods. In the first period, they receive an initial wealth, $W_{i 0}$, and a limited information processing capacity, $\kappa$. In the second period, investors decide their optimal attention allocation between the two countries. In the third period, after receiving a private signal, which depends on the attention allocation, and freely observing prices, investors choose their optimal asset demand. In the last period, investors consume their portfolio.

\subsection{Information Processing}

Investors optimally decide how much information they want to process about each risky asset. Investors would like to choose a private signal that reduces all their uncertainty about the asset payoffs. However, investors face a technological constraint which is called information processing constraint that restricts the amount of information they can process. 
Investors are constrained to choose a signal of the following form

$$
\tilde{Y}_{i}=C_{i} \tilde{R}+\tilde{\varepsilon}_{i} \text { where } \tilde{\varepsilon}_{i} \sim N\left(0, \Sigma_{i}\right)
$$

where $C_{i}$ is any $k \times 2$ matrix, $\tilde{\varepsilon}_{i}$ is independent of $\tilde{R}, \tilde{\varepsilon}_{i}$ is independent of $\tilde{\varepsilon}_{k}$ for $i \neq k$ and $\Sigma_{i}$ is the variance covariance matrix of $\tilde{\varepsilon}_{i}$. The private signal provides information about linear combinations of asset payoffs. The precision of a signal is higher if more attention is allocated to that particular signal. The private signals are incorporated to the investor's beliefs through rational Bayesian updating. Investors optimally find the form of the conditional variance of the payoffs, which is not initially constrained to be diagonal, by choosing $C_{i}$ and $\Sigma_{i}$ subject to the information processing constraint.

Following Sims $(2003,2006)$, we use concepts of information theory to quantify the amount of information that a private signal contains about the asset payoffs. The information processing constraint is given by

$$
\ln |\operatorname{Var}(\tilde{R})|-\ln \left|\operatorname{Var}\left(\tilde{R} \mid \tilde{Y}_{i}\right)\right| \leq 2 \kappa
$$

The information constraint restricts the amount of information contained in the private signal. The information constraint is not conditioned on the prices as in Mondria (2006) to avoid multiplicity of equilibria. This constraint implies that prices are freely observable and investors do not waste any capacity by processing them. It gets rid of the information complementarities among investors through the information constraint. If everyone is getting a lot of information, an investor is benefited by observing more informative prices. However, the investor does not benefit from a less tight information constraint. If prices are not very informative or the asset supply is very noisy ${ }^{3}$, then it is equivalent to use an information constraint conditioned on prices or non conditioned on prices.

There is a second constraint that also limits the way an investor can choose a private

\footnotetext{
${ }^{3}$ Learning from prices is a challenging task for investors. They need to know the market structure, the behaviour of liquidity traders, the preferences and the information processing capacity of other investors. For simplicity, we do not conditon the information processing constraint on prices.
} 
signal. The no-forgetting constraint restricts investors from forgetting information already known in order to process other types of information and it is given by

$$
\operatorname{Var}(\tilde{R})-\operatorname{Var}\left(\tilde{R} \mid \tilde{Y}_{i}\right) \text { positive semidefinite }
$$

This constraint rules out the possibility that investors increase their uncertainty about an asset in order to reduce more uncertainty about another asset.

Investors, with absolute risk tolerance parameter $\rho$, maximize their mean-variance objective function

$$
U_{i}=E\left(E\left[W_{i}^{\prime} \mid \tilde{Y}_{i}, \tilde{P}\right]-\frac{1}{2 \rho} \operatorname{Var}\left[W_{i}^{\prime} \mid \tilde{Y}_{i}, \tilde{P}\right]\right)
$$

subject to the budget constraint

$$
W_{i}^{\prime}=W_{i 0} R+X_{i}^{\prime}(\tilde{R}-R \tilde{P})
$$

where $W_{i 0}$ is the initial wealth of agent $i, X_{i}=\left(x_{i, 1}, x_{i, 2}\right)^{\prime}$ is the asset holdings vector of agent $i, \tilde{R}$ is the vector of risky asset payoffs and $\tilde{P}$ is the price vector of the risky assets. The market clearing conditions are given by $\int_{0}^{1} X_{i} d i=\tilde{Z}$.

Investors devote their limited attention to process information about the asset payoffs. After choosing the form of the private signal, investors decide the amount of information they want to process about each stock market. Then, investors incorporate the information from

their optimally chosen private signal, $\tilde{Y}_{i}$, and the price into their beliefs through Bayesian updating. After investors derive their posterior beliefs about the asset payoffs, they decide their optimal asset holdings.

\subsection{Solution}

The model is solved using backward induction. First, given an arbitrary attention allocation, each agent decides the optimal asset holdings. Second, given the optimal risky asset demand for each attention allocation, each agent decides the optimal attention allocation. 


\subsubsection{Optimal Asset Holdings}

In the third period, after observing the private signals and the asset prices, investors derive their posterior beliefs about the asset payoffs in order to choose their optimal asset holdings

$$
X_{i}\left(\tilde{Y}_{i}, \tilde{P}\right)=\rho \operatorname{Var}\left[\tilde{R} \mid \tilde{Y}_{i}, \tilde{P}\right]^{-1} E\left[\tilde{R}-R \tilde{P} \mid \tilde{Y}_{i}, \tilde{P}\right]
$$

The rational expectations equilibrium price is found by aggregating these asset demands and imposing the market clearing conditions as in Admati (1985).

Proposition 1 There exists a unique linear rational expectations equilibrium price that depends on both market aggregates

$$
\tilde{P}=A_{0}+A_{1} \tilde{R}-A_{2} \tilde{Z}, \text { with } A_{2} \text { nonsingular }
$$

Expressions for $A_{0}, A_{1}$ and $A_{2}$ are in the appendix. The optimal asset holdings by an investor $i$ are given by

$$
X_{i}\left(\tilde{Y}_{i}, \tilde{P}\right)=G_{0 i}+G_{1 i} \tilde{Y}_{i}-G_{2 i} \tilde{P}
$$

Expressions for $G_{0}, G_{1}$ and $G_{2}$ are in the appendix.

\subsubsection{Optimal Attention Allocation}

In the second period, investors decide the form of the private signal and the amount of information they want to process about each market.

The objective function in the second period is found by introducing the optimal asset holdings in the objective function and taking the expected value. Investors maximize

$$
\max _{C_{i}, \Sigma_{i}^{-1}} \operatorname{Tr}\left(V_{i}^{-1} Q_{i}\right)+E R^{\prime} V_{i}^{-1} E R
$$


where

$$
\begin{aligned}
& V_{i}=\operatorname{Var}\left[\tilde{R} \mid \tilde{Y}_{i}, \tilde{P}\right] \\
& E R=E\left[E\left(\tilde{R} \mid \tilde{Y}_{i}, \tilde{P}\right)-R \tilde{P}\right] \quad Q_{i}=\operatorname{Var}_{i}\left(E\left(\tilde{R} \mid \tilde{Y}_{i}, \tilde{P}\right)-R \tilde{P}\right)+V_{i}
\end{aligned}
$$

subject to the information constraint

$$
\left|I+\Sigma_{R i}^{-1} C_{i}^{\prime} \Sigma_{i}^{-1} C_{i}\right| \leq \exp (2 \kappa)
$$

Proposition 2 Each investor allocates all the limited capacity, $\kappa$, to learn about one linear combination of asset payoffs. $C_{i}$ is a $1 \times 2$ matrix.

$$
\tilde{Y}_{i}=c_{h i} \tilde{r}_{h}+c_{f i} \tilde{r}_{f}+\tilde{\varepsilon}_{i}
$$

Investors choose to process information about their portfolio. As long as they are interested in holding both types of assets, investors have incentives in observing a linear combination of the asset payoffs, which is always an available option as pointed out by $\operatorname{Sims}(2003,2006)$. Since $C_{i}=\left(c_{h i}, c_{f i}\right)$ is a $1 \times 2$ matrix, then $\Sigma_{i}^{-1}$ is a scalar. Since investors only care about the relative weight that each risky asset has in the private signal, a normalization is necessary so that $c_{h i}=1$ or $C_{i}=\left(1, c_{f i}\right)$.

Investors choose to observe a linear combination of asset payoffs as a private signal since they are interested in processing information about their diversified portfolio. Even if investors processed information about only one of the assets, they would be interested in holding the other risky asset because of international diversification. This is the reason why it is not optimal to process information about only one asset. Intuitively, as in Mondria (2006), given their well diversified portfolio, the relevant state variable is a linear combination. The most efficient way to process information about their variable of interest is by processing information about the linear combination. Otherwise, by processing information about each asset separately, investors are wasting capacity when updating their private information through 
Bayesian updating. ${ }^{4}$

Proposition 3 If there is no information advantage, $\phi=1$, there exists a unique equilibrium in which all investors allocate their attention to learn about the same linear combination of asset payoffs, $C=\left(1, c_{f}^{*}\right)$

$$
c_{f}^{*}=\frac{\left(\sigma_{r f}^{2} \sigma_{z f}^{2}+\sigma_{r f}^{2} \bar{z}_{f}^{2}-\sigma_{r h}^{2} \sigma_{z h}^{2}-\sigma_{r h}^{2} \bar{z}_{h}^{2}\right)+\sqrt{\left(\sigma_{r f}^{2} \sigma_{z f}^{2}+\sigma_{r f}^{2} \bar{z}_{f}^{2}-\sigma_{r h}^{2} \sigma_{z h}^{2}-\sigma_{r h}^{2} \bar{z}_{h}^{2}\right)^{2}+4 \sigma_{r h}^{2} \sigma_{r f}^{2} \bar{z}_{h}^{2} \bar{z}_{f}^{2}}}{2 \sigma_{r f}^{2} \bar{z}_{h} \bar{z}_{f}}
$$

and investors choose $\Sigma_{i}$ to be

$$
\Sigma_{i}^{-1}=\frac{\left(e^{2 \kappa}-1\right)}{\sigma_{r h}^{2}+c_{f}^{*} \sigma_{r f}^{2}}
$$

which exist as long as a parameter constraint is satisfied

$$
Q_{h f}>-\bar{Q}
$$

Expressions for $Q_{h f}$ and $\bar{Q}$ are also in the appendix.

If there is no information advantage, there exists a unique equilibrium in which all investors observe the same linear combination as a private signal ${ }^{5}$ and there is no home bias. The equilibrium exists as long as a parameter constraint is satisfied. The constraint restricts the covariance of the excess returns, $Q_{h f}$, from being too negative. If this constraint is not satisfied, investors are able to create a well diversified portfolio that reduces their uncertainty about the world economy and an imperfect information equilibrium does not exist.

If domestic investors have an information advantage in domestic assets, then different types of investors choose different private signals. Domestic investors optimally choose to observe a private signal with a higher weight in the domestic asset. Thus, domestic investors tilt

\footnotetext{
${ }^{4}$ The main difference with Van Nieuwerburgh and Veldkamp (2006) is that they exogenously set the sources of risks that can be learned. If the risky assets are ex ante independent, they assume independence of uncertainty across assets ex post, which means that investors separately collect information about each asset. In other words, they constrain the posterior variance-covariance matrix of the asset payoffs to be diagonal, which means that independent sources of uncertainty are still kept independent ex post, whereas this is not necessarily optimal in a portfolio problem.

${ }^{5}$ Notice that this is the same linear combination that investors would observe if the information processing constraint was conditioned on prices as in Mondria (2006). Therefore, the new information constraint has no effect on the relative attention allocated to each market.
} 
their portfolio towards domestic assets. As a consequence, the initial information advantage is magnified and there is home bias as shown in the following sections.

\subsection{Numerical Example: investment specialization}

Investors optimally decide to specialize in processing information about the asset in which they have an initial advantage because of the interaction of the optimal asset holding and the optimal attention allocation. Intuitively, as stated by Van Nieuwerburgh and Veldkamp (2006), the more information about one asset, the higher are the holdings of that asset. Furthermore, the higher the asset demand, the higher the incentives to process information about the asset.

We run a numerical example ${ }^{6}$ in order to show the optimal investment specialization. Domestic investors have a $10 \%$ initial advantage in domestic assets, $\phi=1.1$. Following Ahearne, Griever and Warnock (2004), home bias is defined as

$$
\text { Home Bias }=1-\frac{\text { Share of foreign equities in U.S. Portfolio }}{\text { Share of foreign equities in World Portfolio }}
$$

As we can see in Figure 1, as long as the information processing capacity, $\kappa$, is higher than zero, investors tilt their portfolio towards the domestic asset and the initial information advantage is magnified. The optimal level of specialization generates a considerable amount of home bias. It is only a bit smaller than the home bias generated by only fully specializing in domestic assets as in Van Nieuwerburgh and Veldkamp (2006). As we explained before, the home bias with optimal specialization is lower than with full specialization because of diversification reasons. Investors want to hold foreign assets to diversify their portfolio. As a consequence, foreign assets are generating volatility in the portfolio and that is why it is optimal to pay some attention to foreign assets. In the full specialization environment, investors are holding foreign assets, but they are not processing any information about them.

In this model investors choose a private signal from a richer set than Van Nieuwerburgh and Veldkamp (2006). As shown in Proposition 2, for any matrix of weights in the private signal,

\footnotetext{
${ }^{6}$ The parameter valuse are the following $\sigma_{r h}=\sigma_{r f}=0.2, \bar{r}_{h}=\bar{r}_{f}=3, \sigma_{z h}=\sigma_{z f}=20, \bar{z}_{h}=\bar{z}_{f}=16$, $\rho=0.5$. The results are robust to changes in all the parameters.
} 
investors decide to allocate all their attention in one private signal. In Van Nieuwerburgh and Veldkamp (2006), when assets are independent, investors are constrained to choose either a signal about the domestic asset or about the foreign asset. In this model, even though investors are able to choose any linear combination among both assets, investors optimally decide to process mostly information about home assets, which substantially tilts their portfolio away from the world portfolio towards domestic assets.

In the same Figure 1, we can also see that the amount of home bias generated by the initial information advantage is small. If there is no information advantage, as in Proposition 3 , then all investors hold the same portfolio and there is no home bias.

Figure 1: Home Bias Magnified

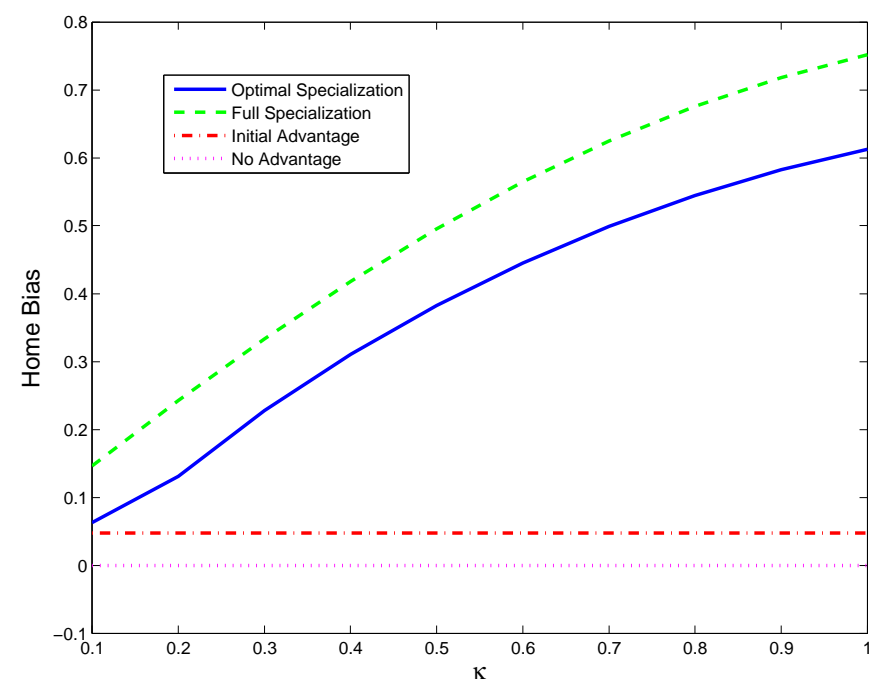

A testable implication of the model is that the more information processing capacity investors have, the more their portfolios are tilted away from the world portfolio towards the domestic assets. Intuitively, the amount of home equity bias depends on what the domestic investor knows relative to the average investor. As the information processing resources increase, the higher is the knowledge wedge between the domestic and the average investor and therefore, the larger is the home bias. In Figure 2, we can see how the attention allocated to domestic assets is increasing with the information processing capacity.

Although Figures 1 and 2 provide a good qualitative and quantitative explanation of the home bias puzzle based on a static model, they also raise a puzzling feature regarding the 
Figure 2: Optimal Attention Allocation

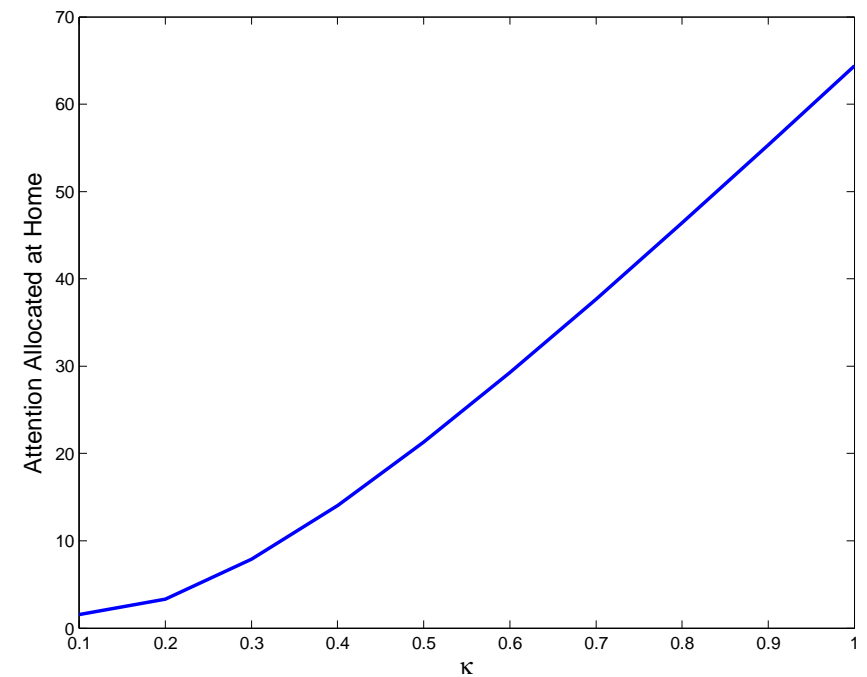

dynamic behavior of the home bias. According to the figures, the higher the information processing capacity, the more attention allocated to domestic assets and the higher the home bias predicted. Therefore, it predicts that the home bias should have increased in the recent years, since the information processing capacity has been increasing over time with better information processing technology. However, the home bias has been decreasing over the last twenty years, as shown by Karolyi and Stulz (2002) and Ahearne, Griever and Warnock (2004).

\section{Introducing Dynamics}

In the section, we examine the dynamics of our model when the asset payoffs follow an autoregressive process. As we have seen in the previous section, investors specialize in processing information about assets in which they have an initial advantage. When the asset payoffs have some persistence, information processed about asset payoffs in the current period is also useful to process information about the asset payoffs in the following period. Thus, the initial advantage is magnified period after period since investors optimally choose to process more information about domestic assets in every period. 


\subsection{Persistent Asset Payoffs}

Let us assume that asset payoffs behave as an $A R(1)$

$$
\begin{aligned}
\tilde{R}_{t+1} & =F \tilde{R}_{t}+\tilde{v}_{t+1} \text { where } \tilde{v}_{t+1} \sim N\left(0, \Sigma_{v}\right) \\
\Sigma_{v} & =\left(\begin{array}{cc}
\sigma_{v, h}^{2} & 0 \\
0 & \sigma_{v, f}^{2}
\end{array}\right) \text { and } F=\left(\begin{array}{cc}
f & 0 \\
0 & f
\end{array}\right) \text { where } 0<f<1
\end{aligned}
$$

As in the initial setup, the home investor has an initial advantage in processing information about home assets $\tilde{v}_{h, h} \sim N\left(0, \sigma_{v, h}^{2}\right)$ and $\tilde{v}_{h, f} \sim N\left(0, \phi \sigma_{v, f}^{2}\right)$ where $\phi \geq 1$, while the foreign investor has an initial advantage in processing information about foreign assets $\tilde{v}_{f, h} \sim N\left(0, \phi \sigma_{v, h}^{2}\right)$ and $\tilde{v}_{f, f} \sim N\left(\bar{r}_{f}, \sigma_{v, f}^{2}\right)$ where $\phi \geq 1$. The unconditional variance of the asset payoffs is given by $\operatorname{Var}\left(\tilde{r}_{j t}\right)=\frac{\sigma_{v j}^{2}}{\left(1-f^{2}\right)}$, while the conditional variance of the asset payoffs given information at $t, I_{t}=\left\{\tilde{Y}_{i, h}, \tilde{P}_{h}\right\}_{h=0}^{h=t}$, is given by

$$
U_{i, t, t+1}=\operatorname{Var}_{i}\left(\tilde{R}_{t+1} \mid I_{t}\right)=F V_{i, t, t} F+\Sigma_{v} \text { where } V_{i, t, t}=\operatorname{Var}_{i, t, t}\left(\tilde{R}_{t} \mid I_{t}\right)
$$

At each period new assets are issued and pay off at the end of the period. There are no multi period lived assets. For tractability reasons, we assume that at each period $t$ a continuum of two-period lived investors are born and given an initial wealth. Before dying, each investor $i$ gives her information to the next investor $i$ born in the following period ${ }^{7}$. Investors face an information constraint that restricts the amount of information to be processed period after period. Investors choose a private signal that reduces their uncertainty by

$$
\ln \left|\operatorname{Var}_{i}\left(\tilde{R}_{t+1} \mid I_{t}\right)\right|-\ln \left|\operatorname{Var}_{i}\left(\tilde{R}_{t+1} \mid I_{t}, \tilde{Y}_{i, t+1}\right)\right| \leq 2 \kappa
$$

The information constraint imposes a limit reduction to the variance covariance matrix of the posterior variance of the asset payoffs. Investors observe a linear combination of asset payoffs

\footnotetext{
${ }^{7}$ This assumption is taken from Bacchetta and Van Wincoop (2006). This assumption avoids infinitely higher-order expectations to arise in the solution. This technical difficulty is the reason why most noisy rational expectations models are static or two-period models. For an overview, see Brunnermeier (2001).
} 
with a measurement error $\tilde{Y}_{i, t+1}=C_{i, t+1} \tilde{R}_{t+1}+\tilde{\varepsilon}_{i, t+1}$ where $\tilde{\varepsilon}_{i, t+1} \sim N\left(0, \Sigma_{i}\right)$. The conditional variance of $R_{t+1}$ after receiving a private signal is given by

$$
\operatorname{Var}_{i}\left(\tilde{R}_{t+1} \mid I_{t}, \tilde{Y}_{i, t+1}\right)=\left(U_{i, t, t+1}^{-1}+C_{i, t+1}^{\prime} \Sigma_{i, t+1}^{-1} C_{i, t+1}\right)^{-1}
$$

The information processing constraint can be rewritten by introducing equation (3) and (5) into equation (4)

$$
\left|I+U_{i, t, t+1} C_{i, t+1}^{\prime} \Sigma_{i, t+1}^{-1} C_{i, t+1}\right| \leq \exp (2 \kappa)
$$

\subsection{Numerical Example: home bias magnified}

We now solve the model numerically to illustrate the implications of the model when returns are persistent ${ }^{8}$. In Figure 3, we can observe how home bias is magnified when asset payoffs are persistent, $f=0.9^{9}$. In the static model, investors are paying more attention to domestic assets because they have an initial information advantage. The reduction in the posterior variance of the domestic asset payoffs is higher than the reduction in the posterior variance of the foreign asset payoffs. When the asset payoffs are persistent, the information processed in the current period can be used to process information about the asset payoffs of the following period. Thus, in the following period, the initial advantage is larger than before since investors processed more information about domestic assets during the previous period. Thus, the initial information advantage is magnified period after period providing incentives to domestic agents to hold more and more domestic assets.

Investors tend to allocate more attention to domestic assets through time and the home bias is increasing over time. It is also worthwhile to note that, as in the static model, the higher the information processing capacity, $\kappa$, the higher the level of home bias. In Figure 4, we can also see how the attention allocated to domestic assets is also increasing through time. The reason is that investors are tilting their portfolio more towards home and more

\footnotetext{
${ }^{8}$ All the parameters of the numerical example are the same specified above.

${ }^{9}$ This number is approximately the estimated first-order autocorrelation of the annual price levels for the Dow Jones Industrial Average, the NYSE Composite and the S\&P 500 indices between 1980 and 2004. See Appendix B for details.
} 
Figure 3: Home Bias Magnified

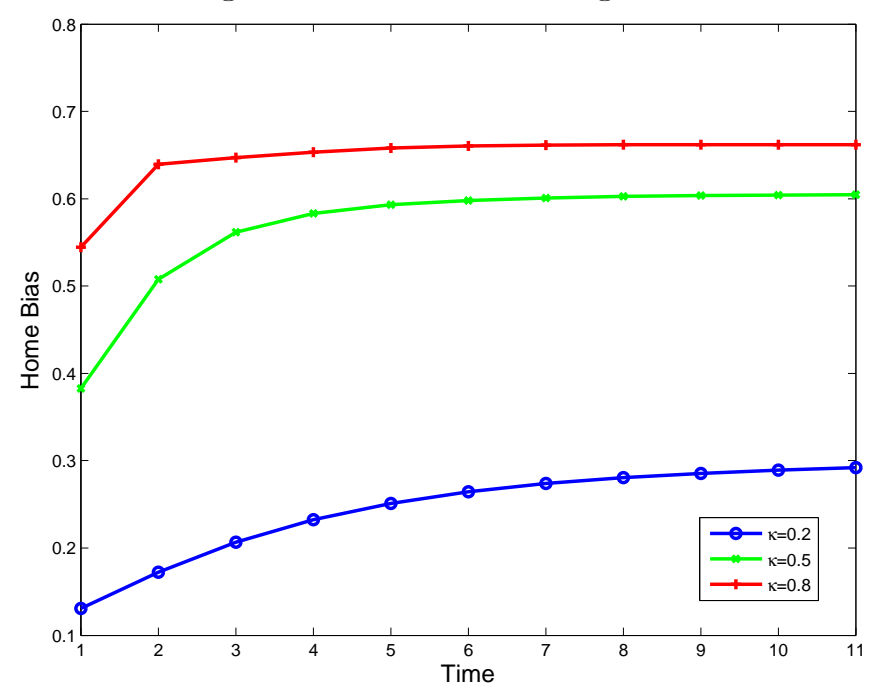

information is required to be processed about domestic assets.

Figure 4: Optimal Attention Allocation

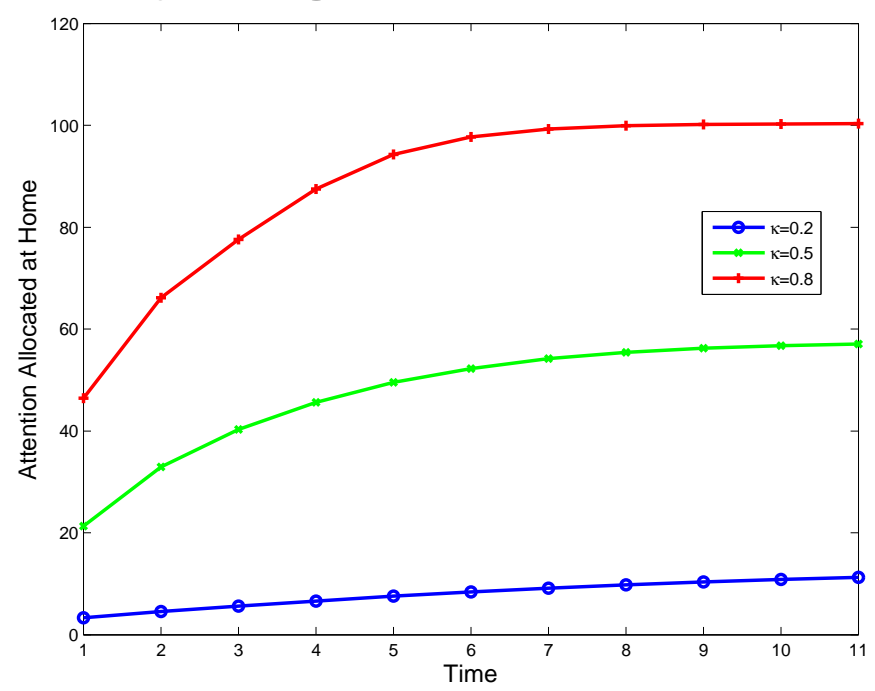

The introduction of persistent asset payoffs increases the home bias in ten percentage points relative to the static model and generates a home bias of almost $70 \%$ when $\kappa=0.8$, which is similar to the $76 \%$ of home bias in U.S. ${ }^{10}$. However, in terms of dynamics, it generates an increase in the home bias over time.

\footnotetext{
${ }^{10} \mathrm{~A}$ higher information processing capacity, $\kappa$, would generate an even larger amount of home bias.
} 


\section{Explaining the Behavior of Home Bias}

\subsection{The Puzzling Evolution of Home Bias}

Figure 5, from Ahearne, Griever and Warnock $(2004)^{11}$, shows the evolution of the share of domestic equities and the evolution of the home bias in the US portfolio from the first quarter of 1980 until the last quarter of 2000. Between 1980 and 1985, American investors had, in average, $98.5 \%$ of their portfolios in domestic equities. As a result, the home bias averaged a high $96.8 \%$ during that period. Between 1985 and 1994, the share of domestic assets in the US portfolio decreased almost 10\%, and after 1994 it has stabilized in its current level, around 89.5\%. The home bias sharply decreased from its previous level until reaching $83.6 \%$ in 1994 , and although it has marginally decreased after that year, averaging $78 \%$ in 2000 , this observed slight decrease was not significant. Kho, Stulz and Warnock (2006) found that "the average home bias of US investors towards the 47 countries with the largest equity markets did not fall from 1994 to 2004 when countries are equally weighted".

Figure 5: Home Bias and Share of Domestic Equities in US Portfolio

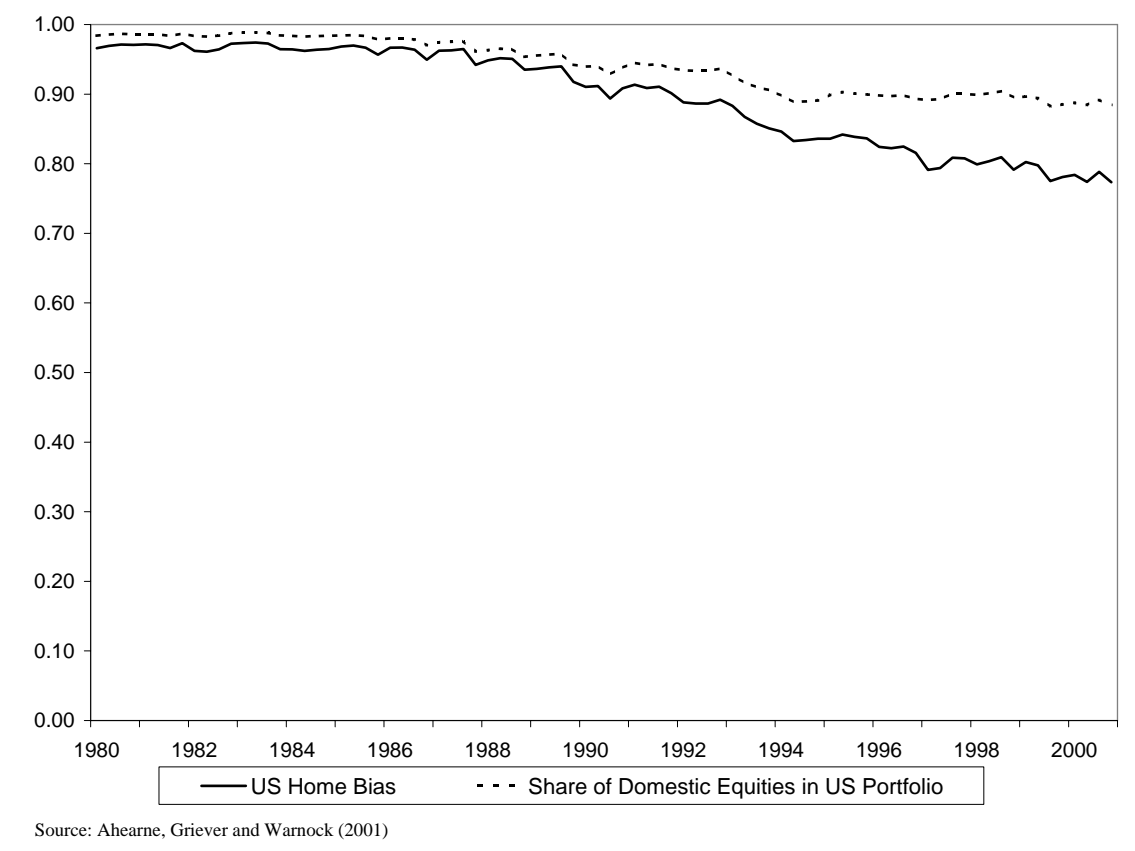

However, the preliminary results obtained in the previous sections predict that home bias

\footnotetext{
${ }^{11}$ We would like to thank Frank Warnock for kindly providing us with the data for this graph.
} 
should have significantly increased in the past years. We showed that the degree of home bias is higher the higher the information capacity, and that this effect is magnified when we considered persistence in assets payoffs. Given that the massive amount of innovations experienced in information technology has greatly increased investors' access to information, home bias should have increased. Figure 6 illustrates this phenomenon by presenting the evolution of the number of internet users (per 1000 people) between 1990 and 2004 for the US, for the average of the industrialized countries and also for the average of the emerging market economies. The figure draws attention not only because of the high internet penetration levels achieved in 2004 (more than 60\% of the US population had access to the internet in 2004, and for the industrialized counties, the average is more than 50\%) but also because of the speed with which these penetration levels were reached.

Figure 6: Internet Users (per 1,000 people)

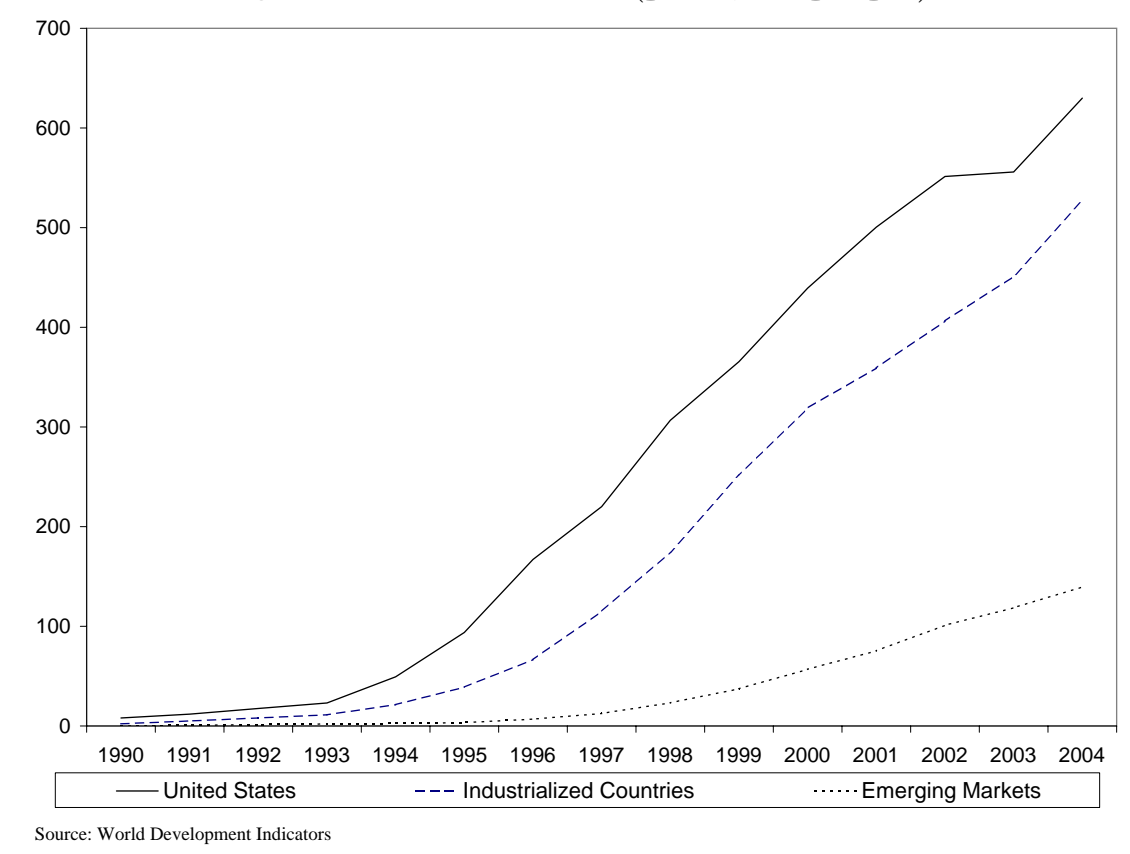

This smoothing transition in the home bias and post-1994 stability is also puzzling when we take into account the speed and depth with which institutional barriers to financial trade have been removed during the 80's, increasing both de jure and de facto financial openness across countries. According to models based on institutional factors, a significant drop in the 
degree of home bias should have already been observed. Figures 7 and 8 show the evolution of two different measures of financial openness from 1970 until 2004. The Chinn and Ito Capital Openness Index is a de jure measure of financial openness that focuses on regulatory restrictions on capital account transactions reported by the IMF. The Lane-Milesi-Ferretti measure of International Financial Integration is a de facto measure of financial openness based on the volume of a country's stocks of external assets and liabilities relative to its GDP. ${ }^{12}$ The US illustrates the difference between the two indices. The US has never officially imposed capital account restrictions according to the IMF criteria. Therefore, it has registered the maximum level of de jure financial openness throughout the whole time span. On the other hand, actual US financial flows reveal that the US has been less financially open relative to both the average industrialized country and the average emerging market economy. Differences aside, both indices tell the same story when we look at the time path of the average financial openness for developed and emerging economies. In the 70's, the economies were almost in financial autarky. There was very little financial openness, both de jure and de facto. There were many barriers to international trade in assets and as a consequence the observed volume of financial trade was very small. During the 80 's, as institutional restriction to international financial investment were being removed in most of the developed economies, the Chinn and Ito Capital Openness Index sharply increased, reaching a level close to the maximum around 1993. The actual volume of financial trade responded to the higher degree of liberalization. The average sum of the financial assets and liabilities divided by the GDP for the developed economies doubled from less than 1 in 1980 to almost 2 in 1995 and then reached 4.5 in 2004 .

It turns out that only when we combine financial openness with persistent payoffs are we able to explain the time series behavior of the home bias - an initial plateau before 1985, then a decrease until 1994, followed by stabilization on another plateau. In the following numerical example, we use our model to simulate the portfolio choices of a country that is forced to live in financial autarky for a couple of periods before opening up to financial transactions. As we will see, the simulated path mimics the observed path described by actual data.

\footnotetext{
${ }^{12}$ More on both indices in the empirical section.
} 
Figure 7: Chinn and Ito Capital Openness Index

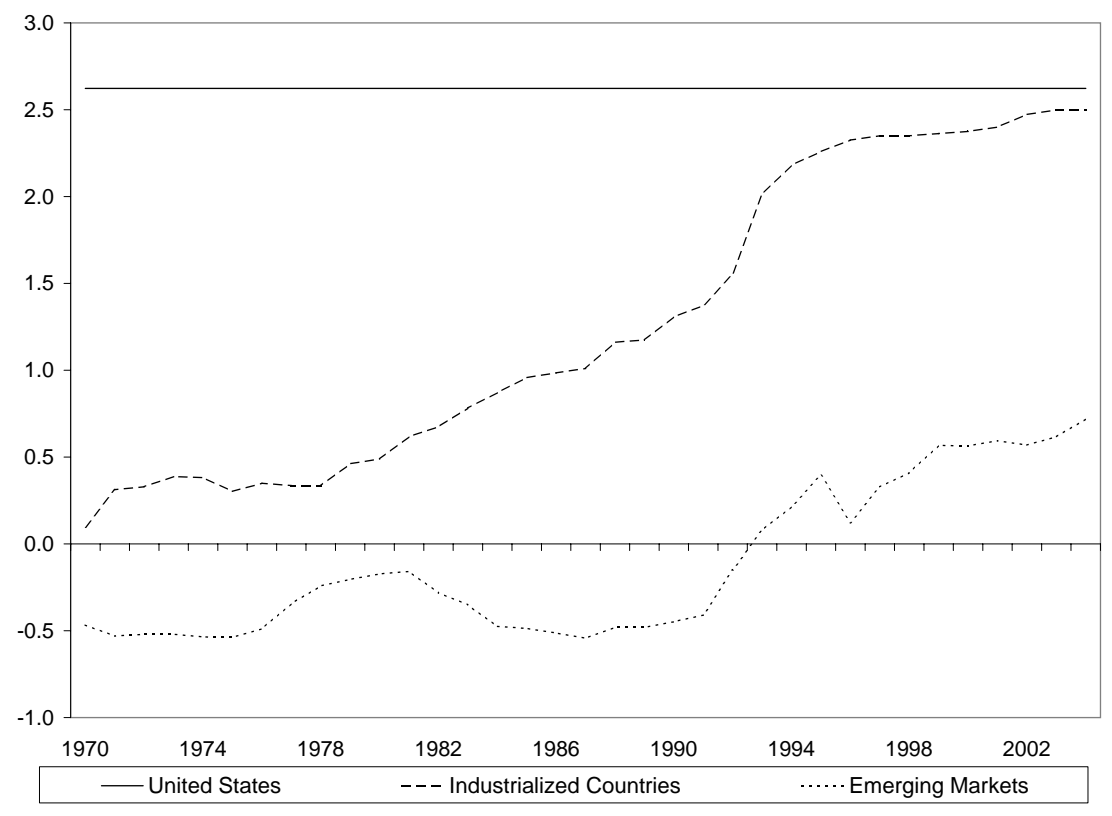

Source: Chinn and Ito (2003)

Figure 8: Lane and Milesi-Ferretti International Financial Integration Measure

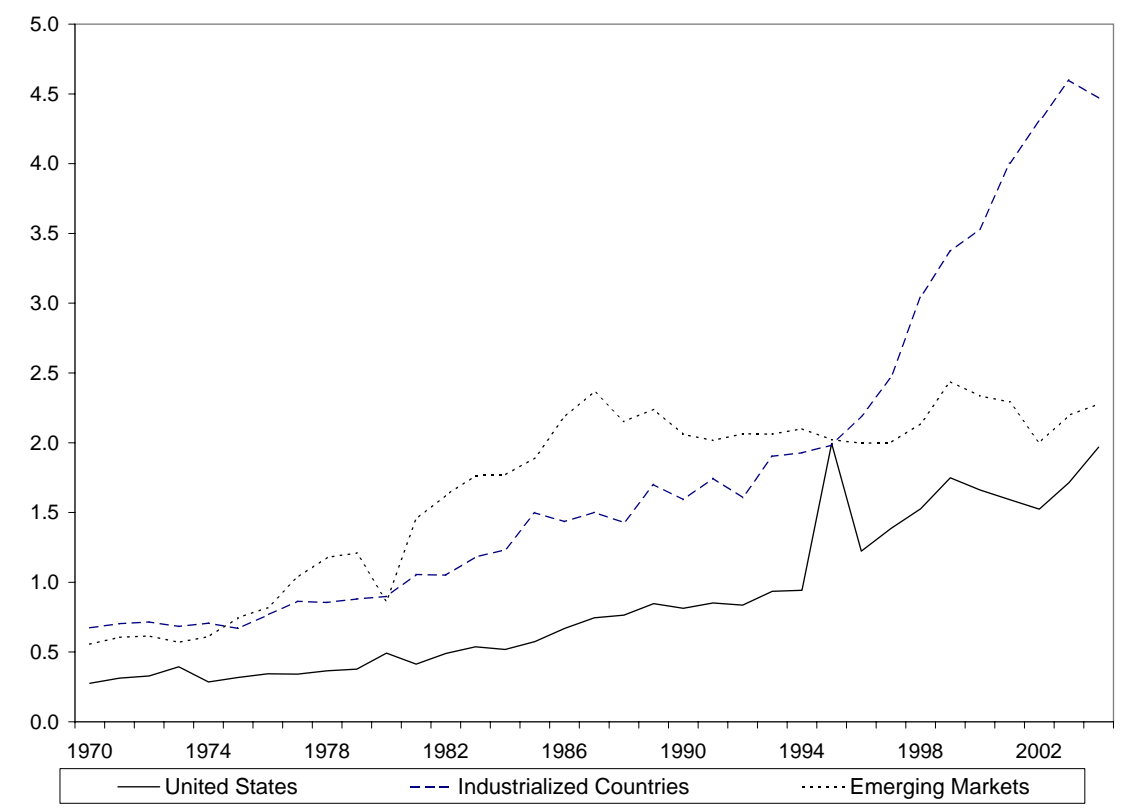

Source: Lane and Milesi-Ferretti (2005) 


\subsection{Numerical Example: adding financial openness}

When there are many restrictions to international trade in assets, the countries are practically behaving as financial autarkies (a situation that resembles the 70's). If investors are only allowed to hold domestic assets, they only process information about domestic assets. When markets are open to the rest of the world, investors have incentives to hold foreign assets in order to obtain gains from diversification. This leads them to start processing information about foreign markets. However, investors have a really big information advantage in processing information about domestic assets because they have been processing information about their home for a long time. Since this information is useful to process information about future asset payoffs, investors will smooth their transition towards holding foreign assets and the home bias decreases through time.

In Figure 9, the asset payoffs are persistent and investors are banned from investing in foreign assets for 5 periods. Therefore, investors have been only holding and processing information about domestic assets. After 5 periods, foreign markets are open. Thus, investors have incentives to hold foreign assets because of diversification reasons. At first, there is a big jump in the home bias because foreign markets are open at once and in an unanticipated way. There are no problems of sovereign risk, there is no transition in the openness and the information is all immediately available to foreign investors. However, investors mostly hold domestic assets because they have learned so much about home that they want to benefit from their information advantage. The information advantage when the markets are open decreases over time and makes it more desirable for investors to hold foreign assets and to benefit from the gains of diversification. The decline in the home bias is not too large because of the interaction between the optimal attention allocation and the optimal portfolio choice. The better information about domestic assets, the higher the domestic asset holdings. Furthermore, the higher the demand of domestic assets, the greater the incentive to process information about domestic assets. Therefore, in steady state, when investors have small asymmetric prior beliefs, investors optimally decide to hold a portfolio with mostly domestic assets. 
Figure 9: Home Bias Decline

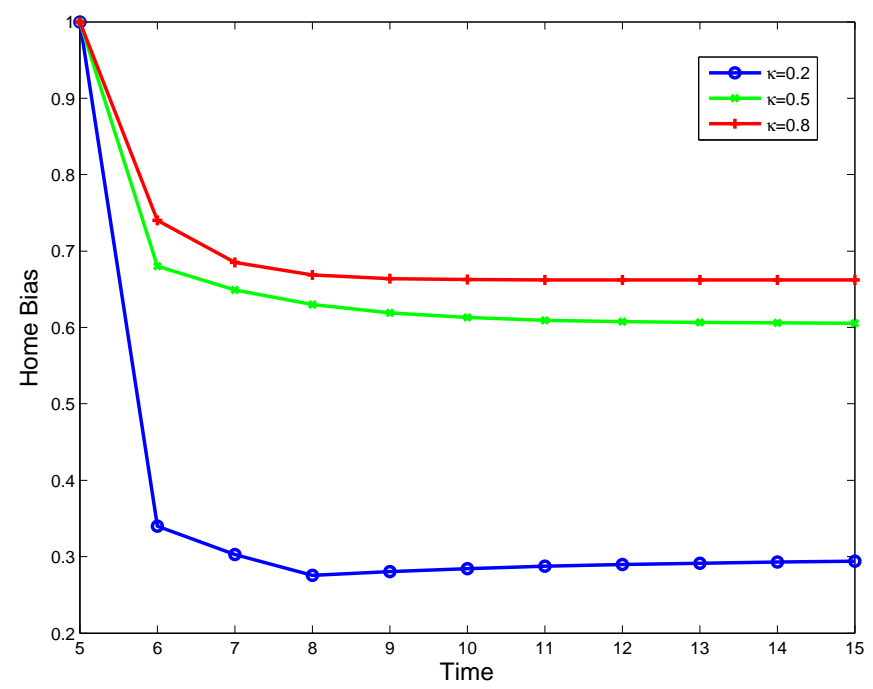

In Figure 10, we observe how the attention allocated in domestic assets behaves after the markets are opened to financial trade. If the economy is in autarky, the amount of attention allocated at home is infinite. When the economy opens, the attention allocated to domestic assets decreases over time because investors start holding and paying attention to foreign assets.

Figure 10: Optimal Attention Allocation

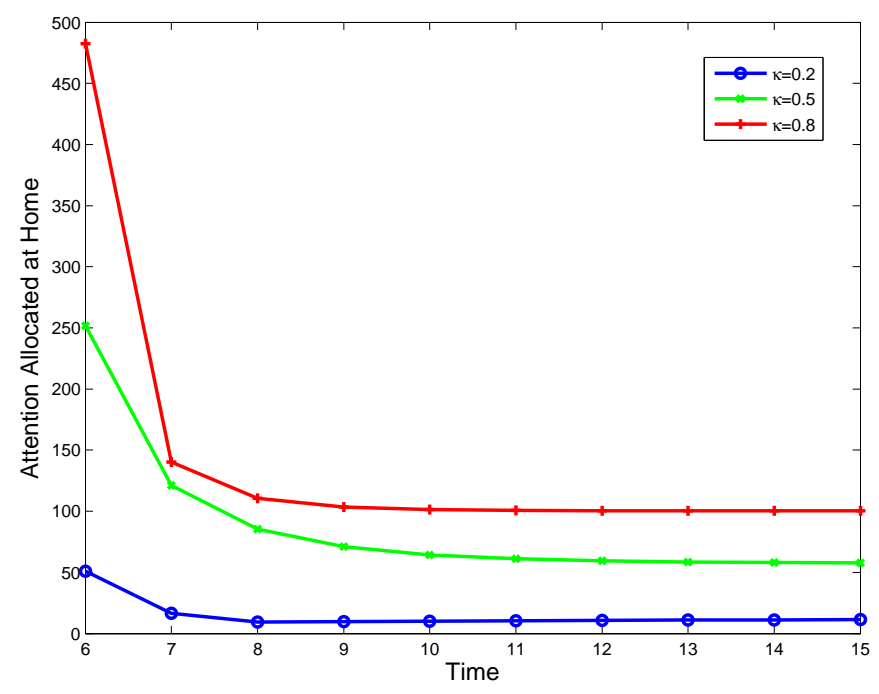

The introduction of financial autarky in the model for a number of periods generates a smooth decline in the home bias followed by stabilization in a new plateau, as shown by 
Karolyi and Stulz (2002) and Ahearne, Griever and Warnock (2004). Investors face a trade off between exploiting their large information advantage and diversification that smooths the transition to foreign asset holdings after a financial liberalization.

\section{Empirical Evidence}

Numerical simulations of the model presented in this paper yielded three basic predictions: (1) home bias increases with (home) information advantage; (2) home bias decreases with financial openness; and (3) home bias increases with information capacity. In this section, we will test these predictions.

\subsection{Data}

The dataset includes measures of home bias, information capacity and financial openness for 19 industrialized countries ${ }^{13}$ during 17 years (1988-2004). The countries are: Australia, Austria, Belgium, Canada, Denmark, Finland, France, Germany, Iceland, Italy, Japan, Netherlands, New Zealand, Portugal, Spain, Sweden, Switzerland, United Kingdom, and the United States. Table (1) to (3) presents summary statistics.

\subsubsection{Home Bias}

For each country $i$ in each year $t$, we use market capitalization data from the World Bank's World Development Indicators database to calculate the share of foreign ${ }^{14}$ equities in the world portfolio, $s f e_{i t}^{\text {world }}$. Then we combine the market capitalization data with international investment position in equity securities data, both in assets and in liabilities, from the IMF's International Financial Statistics database, to calculate the share of foreign equities in a country's portfolio, $s f e_{i t}^{\text {country }}$. With these two shares in hand, we calculate the degree of

\footnotetext{
${ }^{13}$ We started with the 22 industrialized countries, but we eliminated the 3 countries that only had observations for less than half of the time span.

${ }^{14}$ The term "foreign" is from point of view of country $i$.
} 
Table 1: Summary Statistics

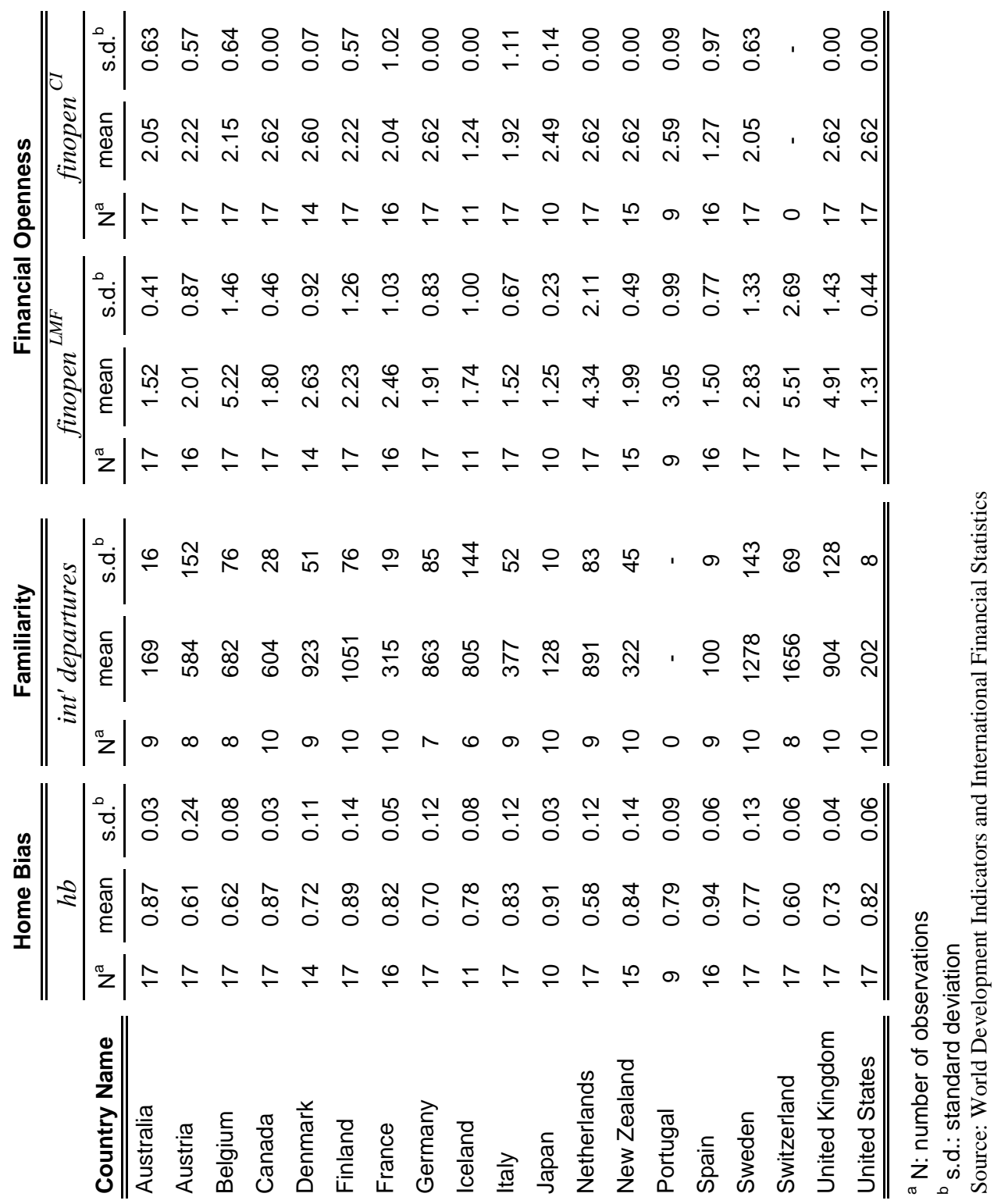


Table 2: Summary Statistics (continued)

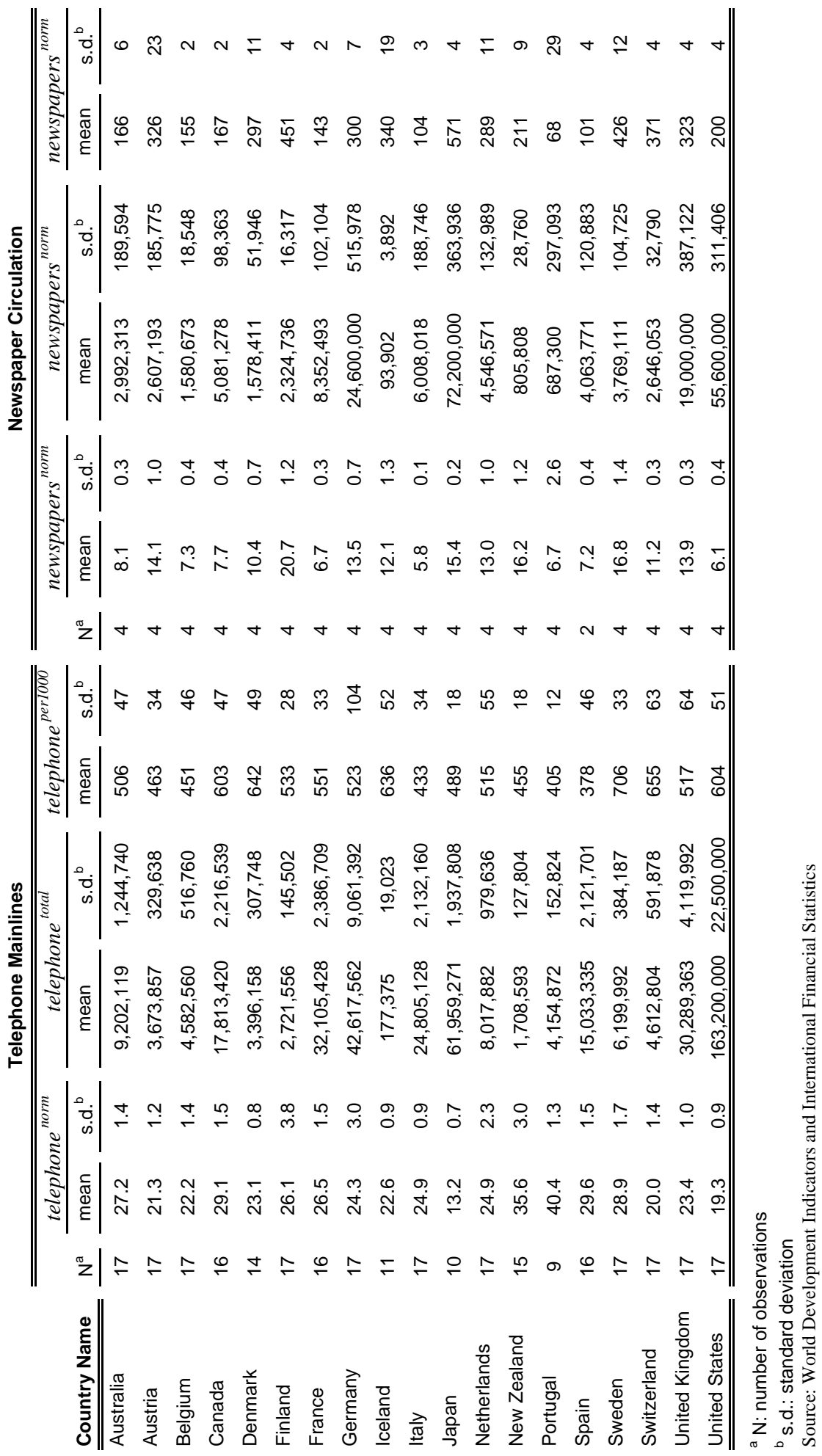


Table 3: Summary Statistics (continued)

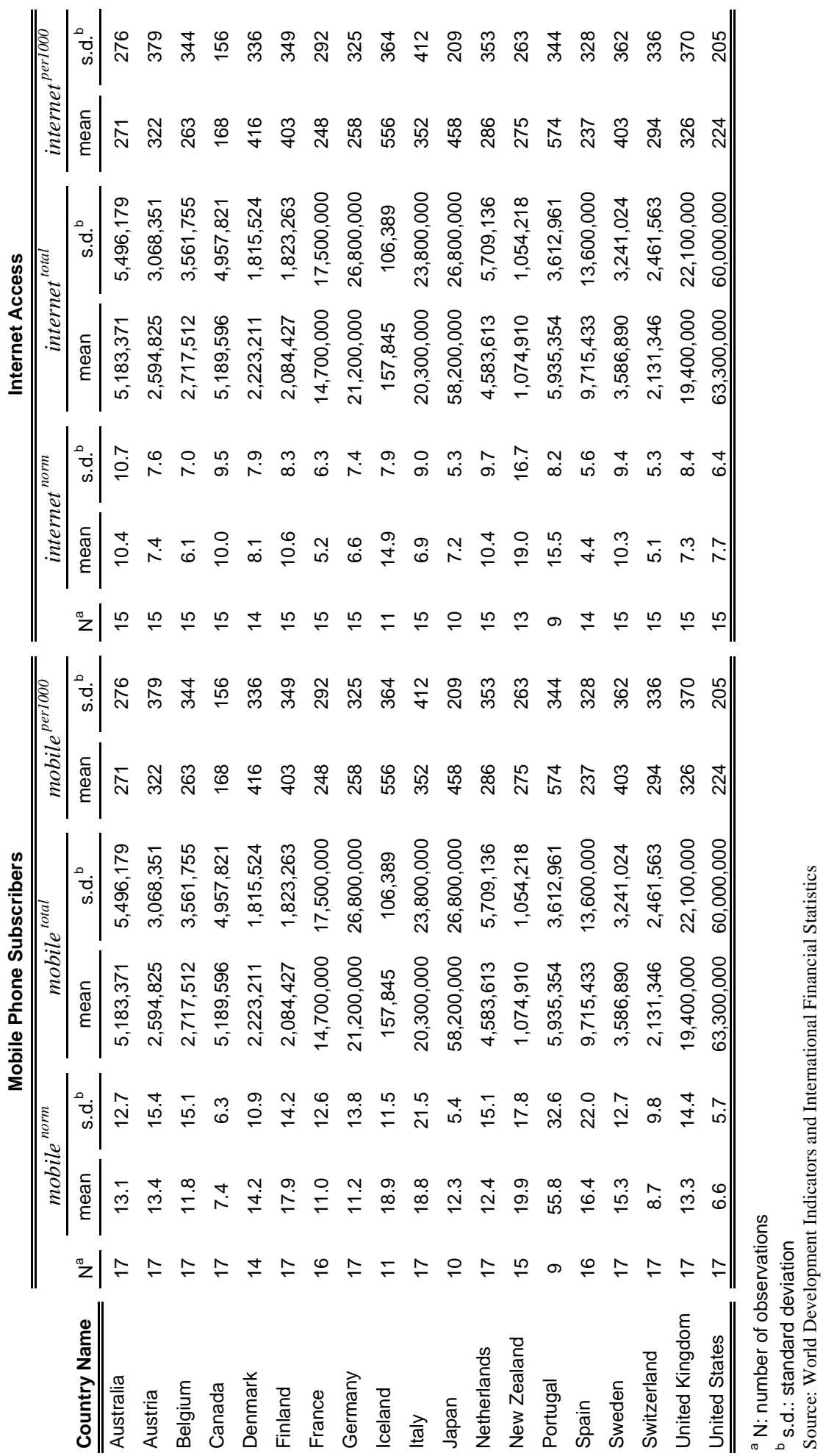


home bias, $h b_{i t}$, following the definition in Ahearne, Griever and Warnock (2004):

$$
h b_{i t}=1-\frac{s f e_{i t}^{\text {country }}}{s f e_{i t}^{\text {world }}}
$$

\subsubsection{Information Capacity}

Sims (2006) emphasizes the distinction between limitations in "wiring" capacity and internal human capacity. The former refers to periodical subscriptions, telephone lines, internet connections and other types of communication technology that allows an agent to access information that is freely available in the outside world. The latter refers to human decision making limitations, or how efficiently the information that was accessed through the "wires" is used when real actions are taken. In this paper, we focus on "wiring" capacity, since it can be measured with a lesser degree of subjectivity.

The World Bank's World Development Indicators database includes four different measures of "wiring" capacity: the average circulation (or copies printed) of newspapers published at least four times a week; the number of telephone mainlines; the number of mobile telephone subscribers to a public mobile telephone service using cellular technology; and the number of people with access to the internet.

In our baseline specification, we will choose telephone lines as the representative of a country's communication technology. This choice is based on a couple of reasons. First, data for this technology is available for all countries in almost every year of our sample, which is not the case for newspapers. Second, fixed telephone lines represented a mature technology in all these countries during all these periods, as opposed to internet or mobile phones, which became popular only in the late 90's. Third, this choice is along the lines of Portes and Rey (2005) analysis of cross-border equity flows: they show that telephone call traffic is a good proxy for overall information flow between two countries. Fourth, Comin, Hobijn and Rovito (2006) show that a country's relative position in the ranking of adoption of a specific technology is highly correlated to its relative position in the ranking of adoption of other technologies. They report that "the median correlation of country ranking across technologies within the OECD is 0.54 ". This means that the country with greater capacity 
in terms of telephone mainlines is most likely the country with greater capacity in other telecommunication technologies. ${ }^{15}$

We take as our main measure of a country's information capacity the number of telephone mainlines per 1,000 people normalized by a country's GDP per capita (in thousands of US dollars), telephone $e_{i t}^{\text {norm }}$. The intuition for this normalization is that we want to compare the channel capacity available to individuals when they are taking real actions with similar economic value. In practical terms, we are calculating the average number of phone lines available to 1,000 individuals when each individual is engaging in an economic activity that is worth $\$ 1,000$ of his own annual income. One simple example can illustrate the effect of our normalization. Imagine that we would like to compare two individuals. In a given year, individual A had one phone line available and he produced $\$ 1,000$ of economic activity. Individual B had two phone lines available and produced $\$ 4,000$ of economic activity. Without normalization, we would say that individual B had a greater channel capacity. But when we normalize, we take into account that individual B had only half of a phone line available for every action that was worth $\$ 1,000$ in terms of economic activity. Therefore, we would consider individual A to have a greater channel capacity. This normalization also eliminates size effects, both in terms of population, that will become clear in the robustness checks. Nevertheless, we will show that we find similar results if we use the total number of telephone lines within a country, telephone $e_{i t}^{\text {total }}$, or the number of telephone lines per 1,000 people, telephone ${ }_{i t}^{\text {per } 1000}$.

The same normalizations will be applied to the other three measures of information capacity that will be used in the robustness checks. That is, we will also present results using the total number, the number per 1,000 people, and the number per 1,000 normalized by the per capita GDP of newspapers, internet and mobile as explanatory variables.

\subsubsection{Financial Openness}

We also include two measures of financial openness: the Chinn-Ito Index of Financial Openness, finopen ${ }_{i t}^{C I}$, and the Lane-Milesi-Ferretti Measure of International Financial Integration,

\footnotetext{
${ }^{15}$ However, their analysis is not limited to telecommunication technologies. They also consider technologies in other areas, such as: agriculture, finance, health, steel, textile, tourism and transportation.
} 
finopen $_{i t}^{L M F}$. The Chinn-Ito Index is the standardized principal component of four binary dummy variables reported in the IMF's Annual Report on Exchange Arrangements and Exchange Restrictions (AREAER). These variables are: (1) the presence of multiple exchange rates, (2) the existence of restrictions on current account transactions, (3) the existence of restrictions on the capital account transactions, and (4) the requirement of the surrender of export proceeds. The Lane-Milesi-Ferretti volume-based measure of International Financial Integration is constructed as the sum of a country's stocks of external assets and liabilities divided by its GDP, and has the same intuition of volume-based measures of trade openness (sum of exports and imports divided by GDP).

By construction, the Chinn-Ito Index is a de jure measure of financial openness, since it focuses on regulatory restrictions on capital account transactions, and the Lane-Milesi-Ferretti measure is a de facto measure of financial openness, since it is based on actual data for capital account flows. We consider both types of measures in our analysis since each has its own drawbacks. The main weakness of de jure measures is that investors may find ways to circumvent capital account restrictions, nullifying the expected effect of the regulatory capital controls. The main weakness of de facto measures is that they may reflect changes in macroeconomic conditions even if there are no regulatory changes on capital account transactions. However, we will show that our results are robust to the choice of measure of financial openness that we use.

\subsubsection{Familiarity}

We also look at a variable that proxies for familiarity with foreign countries, the inverse of (home) informational advantage. This variable, int'l departure, is the number of departures (per 1,000 people) made from their country of usual residence to any other country for any purpose other than a remunerated activity in the country visited. The higher this number, the more familiarized are domestic residents with foreign cultures, and therefore, the smaller the information differential between home and foreign, which means that the informational advantage about home relative to foreign is also smaller. According to our model, the higher the familiarity effect, the smaller the informational advantage and the smaller should be the 
home bias.

It is interesting to notice that our measure of familiarity includes only non-business related international departures. The exclusion of business related international travel is particularly important because of endogeneity reasons. It is not unusual to conduct more international business trips the more you invest abroad. In this case, reverse causality would be an issue. By excluding international trips of business related nature, we are capturing the impact of familiarity effects that are being generated by more general factors on portfolio investment decisions.

\subsection{Estimation Output}

\subsubsection{Basic Specification}

Our basic specification has home bias as the dependent variable and the normalized number of telephone mainlines (per 1,000 people, per $\$ 1,000$ of income per capita) and the Lane-MilesiFerretti volume-based measure of International Financial Integration (the de facto measure of financial openness) as the main explanatory variables. ${ }^{16}$ Table 4 presents the estimation results. The difference between each column is the inclusion (or not) of time effects and country effects.

The first equation does not include any controls for time effects or country effects. We can see that with only two variables, one capturing financial openness and another capturing information capacity, we are able to explain $47 \%$ of the variation of the home bias in our panel. Moreover, both coefficients are significant at the $1 \%$ significance level and have the expected sign. An increase of $1 \%$ in our measure of financial openness decreases the level of home bias by approximately $0.24 \%$, and an increase of $1 \%$ in our measure of information capacity increases the home bias by about $0.22 \%$.

In the second equation, we include time dummy variables. These dummies control for omitted variables that vary through time but are constant across countries. The values of the original coefficients are only marginally changed, and only a small increase in the $R^{2}$ is verified,

\footnotetext{
${ }^{16}$ All variables are in logs, so that the coefficients can be interpreted as elasticities.
} 
from $47 \%$ to $50 \%$. In the third equation, we include only country dummies (fixed effects), in order to control for omitted variables that vary across countries but are constant through time. We observe a significant increase in the $R^{2}$, to $69 \%$. Both coefficients remain significant at the $1 \%$ significance level, but there is a significant increase in the magnitude of the coefficient associated with our measure of information capacity. The fourth equation includes both time and country dummies. Another increase in the $R^{2}$ is noted, to $75 \%$. Both coefficients remain with the expected signs, but have their significance reduced to the $5 \%$ significance level. The magnitude of the home bias elasticity with respect to the financial openness is reduced: an increase of $1 \%$ in the Lane-Milesi-Ferretti measure of financial openness reduces the level home bias by $0.07 \%$. The magnitude of the home bias elasticity with respect to the information capacity is still larger than the one obtained in the first equation: an increase of $1 \%$ in the normalized number of telephone mainlines increases the level home bias by $0.28 \%$.

Table 4: Basic Specification Estimation Output

\begin{tabular}{|c|c|c|c|c|c|c|}
\hline \multicolumn{7}{|c|}{$\begin{array}{l}\text { Dependent Variable: Home Bias } \\
\text { Frequency: annual } \\
\text { Sample Period: } 1988 \text { to } 2004 \\
\text { Country Sample: } 19 \text { Industrialized Countries }\end{array}$} \\
\hline Regressor & $(1)$ & $(2)$ & (3) & (4) & (5) & (6) \\
\hline finopen $^{L M F}$ & $\begin{array}{c}-0.237^{\star \star \star} \\
(0.015)\end{array}$ & $\begin{array}{c}-0.208^{\star \star \star} \\
(0.016)\end{array}$ & $\begin{array}{c}-0.244^{\star \star \star} \\
(0.027)\end{array}$ & $\begin{array}{c}-0.070^{\star *} \\
(0.031)\end{array}$ & $\begin{array}{c}-0.207^{\star *} \\
(0.074)\end{array}$ & $\begin{array}{c}-0.247^{\star \star *} \\
(0.018)\end{array}$ \\
\hline telephone $e^{\text {norm }}$ & $\begin{array}{c}0.222^{\star * *} \\
(0.045)\end{array}$ & $\begin{array}{c}0.208^{\star \star \star} \\
(0.049)\end{array}$ & $\begin{array}{c}0.349 * \star \star \\
(0.103)\end{array}$ & $\begin{array}{l}0.281^{\star *} \\
(0.126)\end{array}$ & $\begin{array}{l}0.593^{\star} \\
(0.274)\end{array}$ & $\begin{array}{c}0.264^{\star \star \star} \\
(0.081)\end{array}$ \\
\hline Time effects? & no & yes & no & yes & yes & no \\
\hline Country effects? & no & no & fixed & fixed & between & random \\
\hline \multicolumn{7}{|c|}{ F-statistics and p-values Testing Exclusion of Group of Variables } \\
\hline Time effects $=0$ & & $\begin{array}{c}1.32 \\
(0.1862)\end{array}$ & & $\begin{array}{c}4.55 \\
(<0001)\end{array}$ & $\begin{array}{c}0.77 \\
(0.6283)\end{array}$ & \\
\hline Country effects $=0$ & & & $\begin{array}{c}18.01 \\
(<0001)\end{array}$ & $\begin{array}{l}16.90 \\
(<0001)\end{array}$ & & \\
\hline$R^{2}$ & $46.8 \%$ & $50.0 \%$ & $69.1 \%$ & $74.6 \%$ & $69.8 \%$ & $46.8 \%$ \\
\hline
\end{tabular}

Finally, we confirm our results in the last two equations by performing two different types 
of panel estimation. The fifth equation presents the between effects estimates (regression on group means). The coefficient associated to the financial openness remains with similar magnitude and is significant at the $5 \%$ significance level. The coefficient associated to the information capacity increases to 0.59 , although it has its significance reduced to the $10 \%$ level. The last equation presents the results of the random effects estimates. Both coefficients have similar magnitudes, the expected sign and are highly significant (at the $1 \%$ significance level). Furthermore, this regression tells us that, without using any time or country dummy variable, we are able to explain $50 \%$ of the cross sectional variance (the 'between' $R^{2}$ ) and $42 \%$ of the time series variance (the 'within' $R^{2}$ ).

\subsubsection{Robustness Checks}

Taking the fourth equation in Table 4 as our benchmark equation - the regression with time and country fixed effects - we perform five different robustness checks. Table 5 presents the estimation output from each change. The first equation uses the Chinn-Ito Index of Financial Openness (the de jure measure of financial openness ${ }^{17}$ ). In the second and third equations, we change the measure of information capacity: the second equation uses the total number of telephone mainlines while the third equation uses the number of telephone mainlines per 1,000 people. The next two equations exclude the largest countries in terms of market capitalization from the sample. In 1996, the mid-year in our sample, the US market capitalization represented $41.9 \%$ of the world's market capitalization, and Japan, the second largest, represented $15.3 \%$. This means that both countries together were responsible for more than one half of the world's total market capitalization in that year. ${ }^{18}$ The fourth equation excludes the US and the fifth equation excludes both the US and Japan. Table 5 shows that our results are robust to all these changes we have considered. First, coefficients and their standard errors remained fairly similar to the benchmark estimate (correct sign, similar magnitude and significance). Also, the $R^{2}$ from each remained high, ranging between $73 \%$ and $75 \%$.

Finally, we consider one last robustness check. One could argue that our information

\footnotetext{
${ }^{17}$ This variable is not in logs since it can be negative by construction.

${ }^{18}$ In fact, this is true for every year in our sample.
} 
Table 5: Robustness Check Estimation Output

Dependent Variable: Home Bias

Frequency: annual

Sample Period: 1988 to 2004

Country Sample: 19 Industrialized Countries

\begin{tabular}{|c|c|c|c|c|c|c|}
\hline Regressor & (1) & (2) & (3) & (4) & (5) & (6) \\
\hline $\begin{array}{l}\text { Financial } \\
\text { Openness }\end{array}$ & $\begin{array}{l}-0.027^{\star \star} \\
(0.013)\end{array}$ & $\begin{array}{l}-0.064^{\star *} \\
(0.028)\end{array}$ & $\begin{array}{c}-0.073^{\star \star} \\
(0.029)\end{array}$ & $\begin{array}{c}-0.063^{\star \star} \\
(0.031)\end{array}$ & $\begin{array}{c}-0.055^{\star \star} \\
(0.030)\end{array}$ & $\begin{array}{c}-0.071^{\star \star} \\
(0.030)\end{array}$ \\
\hline $\begin{array}{l}\text { Information } \\
\text { Capacity }\end{array}$ & $\begin{array}{l}0.296^{\star \star} \\
(0.145)\end{array}$ & $\begin{array}{c}0.432^{\star \star \star} \\
(0.148)\end{array}$ & $\begin{array}{l}0.301^{\star \star} \\
(0.136)\end{array}$ & $\begin{array}{l}0.286^{\star *} \\
(0.126)\end{array}$ & $\begin{array}{l}0.296^{\star \star} \\
(0.125)\end{array}$ & $\begin{array}{l}0.316^{\star \star} \\
(0.141)\end{array}$ \\
\hline $\begin{array}{l}\text { GDP } \\
\text { per capita } \\
\text { Robustness }\end{array}$ & ecks & - & - & - & - & $\begin{array}{c}0.153 \\
(0.186)\end{array}$ \\
\hline $\begin{array}{l}\text { Financial } \\
\text { Openness }\end{array}$ & finopen $^{C I}$ & finopen $^{L M F}$ & finopen $^{L M F}$ & finopen $^{L M F}$ & finopen $^{L M F}$ & finopen $^{L M F}$ \\
\hline $\begin{array}{l}\text { Information } \\
\text { Capacity }\end{array}$ & telephone $^{\text {norm }}$ & telephone $^{\text {total }}$ & telephone ${ }^{\text {per1000 }}$ & telephone $^{\text {norm }}$ & telephone $^{\text {norm }}$ & telephone $^{\text {norm }}$ \\
\hline Sample & $\begin{array}{l}\text { includes } \\
\text { all countries }\end{array}$ & $\begin{array}{l}\text { includes } \\
\text { all countries }\end{array}$ & $\begin{array}{l}\text { includes } \\
\text { all countries }\end{array}$ & $\begin{array}{l}\text { excludes } \\
\text { US }\end{array}$ & $\begin{array}{l}\text { excludes US } \\
\text { and Japan }\end{array}$ & $\begin{array}{l}\text { includes } \\
\text { all countries }\end{array}$ \\
\hline$R^{2}$ & $73.4 \%$ & $75.0 \%$ & $74.6 \%$ & $74.6 \%$ & $74.4 \%$ & $74.6 \%$ \\
\hline
\end{tabular}

All regressions include time and country dummy variables, which are not reported. White's robust standard errors are given in parentheses under the coefficients, and p-values are given in parentheses under the F-statistics. The symbols ${ }^{*},{ }^{* *}$ and ${ }^{* \star *}$ denote that the individual coefficient is significant at the $10 \%, 5 \%$ and $1 \%$ significance level respectively. 
capacity variable is only statistically significant because it is working as a proxy for a country's level of development. The high overall correlation of 0.71 between the logs of the number of telephone lines per 1,000 people and the per capita GDP suggests that more developed economies have larger overall channel capacity. So it could be the case that the positive and statically significant coefficient is capturing the fact that, for some reason, more developed economies have higher home bias, while channel capacity does not really matter. In order to control for this case, we include per capita GDP in the regression as an additional control. As we can see for the result, this variable is not significant, while the other variables (specially the information capacity variable) remain with correct sign, similar magnitudes and significance.

\subsubsection{Familiarity Effects}

Equations (1) to (4) have home bias as the dependent variable and include the number of international departures (per 1,000 inhabitants) made from the country of usual residence to any other country for any purpose other than a remunerated activity in the country visited, the number of the normalized number of telephone mainlines (per 1,000 people, per $\$ 1,000$ of income per capita) and the Lane-Milesi-Ferretti volume-based measure of International Financial Integration (the de facto measure of financial openness) as the main explanatory variables. Equation (1) does not include any time or country fixed effects, equation (2) includes time effects, equation (3) includes country fixed effects and equation (4) includes both.

Unfortunately, Table 6 and Table 4 (the basic specification) are not directly comparable. Missing observations for $i n t^{\prime} l$ departure reduce the sample by approximately $45 \%$, from 293 to 160 observations. However, we can see that both finopen and telephone have the correct sign, similar magnitudes compared to the coefficients reported in Table 4, and are significant at the $1 \%$ significant level. Interestingly, the number of international departures is also significant at the $1 \%$ significance level with an expected negative sign: as predicted by our model, the higher the familiarity with foreign countries, the lower the degree of home bias.

Finally, equation (5) includes GDP per capita as a control for a country's development level. One could argue that richer economies would have a larger number of international tourist departures and that the significance of the coefficient would actually be capturing the 
Table 6: Familiarity Effects

\section{Dependent Variable: Home Bias}

Frequency: annual

Sample Period: 1988 to 2004

Country Sample: 19 Industrialized Countries

\begin{tabular}{|c|c|c|c|c|c|}
\hline Regressor & (1) & (2) & (3) & (4) & (5) \\
\hline finopen $^{L M F}$ & $\begin{array}{c}-0.210^{* \star *} \\
(0.026)\end{array}$ & $\begin{array}{c}-0.142^{* * *} \\
(0.025)\end{array}$ & $\begin{array}{c}-0.203^{* * *} \\
(0.057)\end{array}$ & $\begin{array}{c}-0.128^{* \star *} \\
(0.047)\end{array}$ & $\begin{array}{c}-0.132^{* * *} \\
(0.049)\end{array}$ \\
\hline telephone $e^{\text {norm }}$ & $\begin{array}{l}0.222^{* \star *} \\
(0.062)\end{array}$ & $\begin{array}{c}0.178^{\star \star \star} \\
(0.064)\end{array}$ & $\begin{array}{c}0.635^{\star \star *} \\
(0.138)\end{array}$ & $\begin{array}{c}0.560^{\star * *} \\
(0.174)\end{array}$ & $\begin{array}{c}0.618^{* * *} \\
(0.118)\end{array}$ \\
\hline int'l departure $^{\text {per1000 }}$ & $\begin{array}{c}-0.060^{* * *} \\
(0.014)\end{array}$ & $\begin{array}{c}-0.083^{* * *} \\
(0.013)\end{array}$ & $\begin{array}{c}-0.279^{* * *} \\
(0.118)\end{array}$ & $\begin{array}{c}-0.233^{\star \star *} \\
(0.113)\end{array}$ & $\begin{array}{l}-0.250^{* *} \\
(0.124)\end{array}$ \\
\hline GDP percapita & - & - & $\begin{array}{l}- \\
-\end{array}$ & - & $\begin{array}{c}0.330 \\
(0.338)\end{array}$ \\
\hline $\begin{array}{l}\text { Time effects? } \\
\text { Country effects? }\end{array}$ & $\begin{array}{l}\text { no } \\
\text { no }\end{array}$ & $\begin{array}{l}\text { yes } \\
\text { no }\end{array}$ & $\begin{array}{c}\text { no } \\
\text { fixed }\end{array}$ & $\begin{array}{l}\text { yes } \\
\text { fixed }\end{array}$ & $\begin{array}{c}\text { yes } \\
\text { fixed }\end{array}$ \\
\hline \multicolumn{6}{|c|}{ F-statistics and p-values Testing Exclusion of Group of Variables } \\
\hline Time effects $=0$ & & $\begin{array}{c}3.96 \\
(0.0002)\end{array}$ & & $\begin{array}{c}4.32 \\
(0.0001)\end{array}$ & $\begin{array}{c}3.84 \\
(0.0003)\end{array}$ \\
\hline Country effects $=0$ & & & $\begin{array}{c}23.08 \\
(<0.0001)\end{array}$ & $\begin{array}{c}16.03 \\
(<0.0001)\end{array}$ & $\begin{array}{c}17.08 \\
(<0.0001)\end{array}$ \\
\hline Number of obs. & 160 & 160 & 160 & 160 & 160 \\
\hline$R^{2}$ & $38.7 \%$ & $45.2 \%$ & $83.3 \%$ & $85.6 \%$ & $85.7 \%$ \\
\hline
\end{tabular}

Dummies variables are not reported. White's robust standard errors are given in parentheses under the coefficients, and $\mathrm{p}$-values are given in parentheses under the F-statistics. The symbols *,** and *** denote that the individual coefficient is significant at the $10 \%, 5 \%$ and $1 \%$ significance level respectively. 
effect of economic development on the home bias. The results show that this is not the case. While GDP per capita is not significant, the number of international tourist departures is significant at the $5 \%$ level with the expected sign.

\subsubsection{Alternative Measures of Information Capacity}

Equations (1) to (3) reports the estimation results of the baseline regression, but each with a different alternative measure of information capacity (all of them normalized by GDP). We can notice that only newspaper is significant at the $5 \%$ level with a predicted positive sign. Mobile phones and internet subscribers were not significant at the $10 \%$ level.

Table 7: Alternative Measures of Information Capacity

\begin{tabular}{|c|c|c|c|c|c|c|c|}
\hline \multicolumn{8}{|c|}{$\begin{array}{l}\text { Dependent Variable: Home Bias } \\
\text { Frequency: annual } \\
\text { Sample Period: } 1988 \text { to } 2004 \\
\text { Country Sample: } 19 \text { Industrialized Countries }\end{array}$} \\
\hline Regressor & $(1)$ & (2) & (3) & (4) & (5) & (6) & (7) \\
\hline finopen $^{L M F}$ & $\begin{array}{l}-0.084^{*} \\
(0.044)\end{array}$ & $\begin{array}{c}-0.084^{\star \star *} \\
(0.031)\end{array}$ & $\begin{array}{c}-0.096^{\star \star \star} \\
(0.037)\end{array}$ & $\begin{array}{c}-0.080^{* *} \\
(0.032)\end{array}$ & $\begin{array}{c}-0.097^{\star *} \\
(0.040)\end{array}$ & $\begin{array}{c}-0.092^{\star \star} \\
(0.038)\end{array}$ & $\begin{array}{l}-0.080^{*} \\
(0.042)\end{array}$ \\
\hline telephone $e^{i}$ & - & - & - & $\begin{array}{c}0.840 \\
(1.060)\end{array}$ & $\begin{array}{c}0.441 \\
(0.702)\end{array}$ & $\begin{array}{c}0.791 \\
(0.924)\end{array}$ & - \\
\hline newspaper ${ }^{i}$ & $\begin{array}{l}0.177^{\star *} \\
(0.079)\end{array}$ & - & - & $\begin{array}{l}0.257^{\star *} \\
(0.115)\end{array}$ & $\begin{array}{l}0.234^{\star *} \\
(0.102)\end{array}$ & $\begin{array}{l}0.248^{* *} \\
(0.106)\end{array}$ & $\begin{array}{l}0.174^{\star \star} \\
(0.078)\end{array}$ \\
\hline mobile ${ }^{i}$ & - & $\begin{array}{l}-0.001 \\
(0.014)\end{array}$ & - & $\begin{array}{l}-0.153 \\
(0.118)\end{array}$ & $\begin{array}{l}-0.173 \\
(0.149)\end{array}$ & $\begin{array}{l}-0.157 \\
(0.121)\end{array}$ & - \\
\hline internet $^{i}$ & - & - & $\begin{array}{c}0.004 \\
(0.010)\end{array}$ & $\begin{array}{l}-0.076 \\
(0.050)\end{array}$ & $\begin{array}{l}-0.047 \\
(0.070)\end{array}$ & $\begin{array}{l}-0.050 \\
(0.060)\end{array}$ & - \\
\hline GDP percapita & - & - & - & - & - & - & $\begin{array}{l}-0.210 \\
(0.366)\end{array}$ \\
\hline \multicolumn{8}{|c|}{ Robustness Checks } \\
\hline Normalization $i$ & norm & norm & norm & norm & per1000 & total & norm \\
\hline Number of obs. & 74 & 294 & 265 & 74 & 74 & 74 & 74 \\
\hline$R^{2}$ & $81.5 \%$ & $74.0 \%$ & $74.6 \%$ & $83.8 \%$ & $83.5 \%$ & $83.8 \%$ & $81.6 \%$ \\
\hline
\end{tabular}

All regressions include time and country dummy variables, which are not reported. White's robust standard errors are given in parentheses under the coefficients, and p-values are given in parentheses under the F-statistics. The symbols *, $* *$ and $* * *$ denote that the individual coefficient is significant at the $10 \%, 5 \%$ and $1 \%$ significance level respectively.

In equations (4) to (6) we estimate the model with all four measures of information capacity (including telephone mainlines) at the same time. The difference between each equation is the normalization adopted, respectively: GDP, per 1,000 people and total number. We can 
notice that the average number of newspaper in circulation is the best measure of information capacity, being the only variable that is significant at the $5 \%$ level, with the expected sign. Once newspaper circulation is included, the number of telephone mainlines is not significant anymore. All three columns also show that the significance of the coefficient associated to newspaper circulation does not depend on the choice of normalization. These results suggest that newspaper is the best measure of information capacity. This is not surprising, if we realize that daily newspaper headlines are still the major source of diffusion of public information. The problem of using newspapers as our baseline measure of information capacity is the number of missing observations, that reduces the sample from 293 to only 74 .

Finally, the last equation includes financial openness, newspaper circulation and also GDP per capita, as a proxy for a country's level of development. We can see that newspaper circulation is still significant at the $5 \%$ level with the correct positive sign while GDP per capita is not. This means that the significance of the information capacity variable is not being caused by its correlation with a country's development level.

\section{Conclusion}

This paper presents a rational expectations model of asset prices with rationally inattentive investors that can explain both the substantial amount of home bias and the time series behavior of the home bias - an initial plateau before 1985, then a decrease until 1994 followed by stabilization on another plateau. After financial markets are liberalized, investors are able to hold foreign assets and gain from international diversification. However, since the information processed while being in autarky can be used to process information about domestic assets in the current period, investors have an endogenous big advantage in holding and processing information about domestic assets. There is a trade off between large endogenous information advantage in domestic assets and diversification. Investors optimally decide to hold most of their portfolio in domestic assets. They also hold and process information about foreign assets because of diversification purposes, but in a modest way. Over time, the large amounts of information processed in autarky about domestic assets are less helpful to predict current asset 
payoffs. Investors gradually tilt their portfolio towards foreign assets and there is decrease in the home bias. However, the decline in the home bias is not too large because of the interaction between the optimal attention allocation and the optimal portfolio choice. The better information about domestic assets, the higher is the domestic asset holdings. Furthermore, the higher the demand for domestic assets, the greater is the incentive to process information about domestic assets. Therefore, in steady state, when investors have small asymmetric prior beliefs, investors optimally decide to hold a portfolio with mostly domestic assets.

We test some predictions of our model on a panel data set on home bias for 19 developed countries from 1988 until 2004, using three groups of variables that try to measure the degree of information capacity, the degree of informational advantage and the degree of financial openness in each of these countries. We consider different measures of a country's information capacity: the average circulation (or copies printed) of newspapers published at least four times a week; the number of telephone mainlines; the number of mobile telephone subscribers to a public mobile telephone service using cellular technology; and the number of people with access to the internet. We proxy for how familiarized the domestic agent is with foreign countries using the number of international departures made from their country of usual residence to any other country for any purpose other than a remunerated activity in the country visited. Financial openness is included using both de facto and de jure measures. Our baseline specifications are able to explain at least $46.8 \%$ of the variation of the home bias in our data set. Our estimates confirm that home bias decreases with financial openness, and increases with information capacity and with informational advantage, as predicted by our model.

\section{References}

[1] Adler, M., and B. Dumas (1983) "International portfolio choice and corporation finance: A synthesis", Journal of Finance 38, 925-984.

[2] Admati, A. (1985) "A Noisy Rational Expectations Equilibrium for Multi-Asset Securities Markets", Econometrica 53, pp. 629-657.

[3] Ahearne, A., W. Griever and F. Warnock (2001) "Information costs and home bias: An analysis of U.S. holdings of foreign equities" Federal Reserve Board, International Finance Division, Working Paper 691, Washington, D.C. 
[4] Bacchetta, P. and E. Van Wincoop (2006) "Can Information Heterogeneity Explain the Exchange Rate Determination Puzzle?", American Economic Review 96, pp. 552-576.

[5] Black, F. (1974) "International capital market equilibrium with investment barriers" Journal of Financial Economics 1, pp. 337-352.

[6] Brennan, M. and H. Cao, (1997) "International portfolio flows", Journal of Finance 52, pp. 1851-1880.

[7] Brunnermeier, M. (2001) "Asset Pricing under Asymmetric Information", Oxford University Press.

[8] Chinn, M. and H. Ito (2005) "What Matters for Financial Development? Capital Controls, Institutions, and Interactions", forthcoming in the Journal of Development Economics.

[9] Comin, D., B. Hobijn and E. Rovito (2006) "Five Facts You Need to Know About Technology Diffusion", NBER Working Paper 11928.

[10] Cooper, I., and E. Kaplanis (1994) "Home bias in equity portfolios, inflation hedging, and international capital market equilibrium", Review of Financial Studies 7, pp. 45-60.

[11] Coval, J, and T. Moskowitz (1999) "Home bias at home: local equity preference in domestic portfolios", Journal of Finance 54, pp. 2045-2073.

[12] French, K. and J. Poterba (1991) "Investor diversification and international equity markets", American Economic Review 81, pp. 222-226.

[13] Gordon, R. and A. Lans Bovenberg (1996) "Why Is Capital So Immobile Internationally? Possible Explanations and Implications for Capital Income Taxation", American Economic Review 86, pp. 1057-1075.

[14] Kang, J. and R. M. Stulz (1997) "Why is there a home bias? An analysis of foreign portfolio equity ownership in Japan", Journal of Financial Economics 46, pp. 3-28.

[15] Karolyi, A. and R. Stulz (2002) "Are financial assets priced locally or globally?", NBER wp8994

[16] Kho, B., R. M. Stulz and F. Warnock (2006) "Financial globalization, governance, and the evolution of the home bias", NBER wp12389.

[17] Kraay, A., N. Loayza, L. Servén and J. Ventura (2001) "Country Portfolios", CEPR discussion paper 2974.

[18] Lane, P. and G. Milesi-Ferretti (2006) "The External Wealth of Nations Mark II: Revised and Extended Estimates of Foreign Assets and Liabilities, 1970-2004", Institute for International Integration Studies Discussion Paper 126.

[19] Mondria, J. (2006) "Financial Contagion and Attention Allocation", Working Paper, University of Toronto. 
[20] Portes, R. and H. Rey (2003) "The Determinants of Cross Border Equity Flows", revised version of CEPR DP 2225 and NBER WP 7336.

[21] Sims, C. (2003) "Implications of Rational Inattention", Journal of Monetary Economics, 50 , pp. 665-690.

[22] Sims, C. (2006) "Rational Inattention: A Research Agenda", The American Economic Review, P\&P Volume 96, pp. 158-163.

[23] Stulz, R. (1981) "On effects of barriers to international investment", Journal of Finance 36, pp. 923-934.

[24] Tesar, L., and I. Werner (1995) "Home bias and high turnover", Journal of International Money and Finance 14, pp. 467-492.

[25] Van Nieuwerburgh, S. and L. Veldkamp (2006) "Information Immobility and the Home Bias Puzzle" Working Paper, NYU.

[26] Zhou, C. (1998) "Dynamic portfolio choice and asset pricing with differential information", Journal of Economic Dynamics and Control 22, pp. 1027-1051.

\section{A Proof of Propositions}

Proof of Proposition 1. The objective function in the third period is a standard mean variance objective function. A closed form solution of a REE can be derived using these five steps, following Admati (1985):

1. Price conjecture

$$
\tilde{P}=A_{0}+A_{1} \tilde{R}-A_{2} \tilde{Z}
$$

2. Derive posterior beliefs

$$
E\left[\tilde{R} \mid \tilde{Y}_{i}, \tilde{P}\right]=B_{0 i}+B_{1 i} \tilde{Y}_{i}+B_{2 i} \tilde{P}
$$

3. Derive optimal demand

$$
X_{i}\left(\tilde{Y}_{i}, \tilde{P}\right)=\rho_{i} \operatorname{Var}\left[\tilde{R} \mid \tilde{Y}_{i}, \tilde{P}\right]^{-1}\left(B_{0 i}+B_{1 i} \tilde{Y}_{i}+\left(B_{2 i}-R I\right) \tilde{P}\right)
$$

4. Impose the market clearing conditions for all markets and compute the endogenous market clearing price variables.

5. Impose rational expectations, that is, the conjectured price function has to coincide with the actual price function.

Equilibrium prices have the following form

$$
\tilde{P}=A_{0}+A_{1} \tilde{R}-A_{2} \tilde{Z}, \text { with } A_{2} \text { nonsingular }
$$


where

$$
\begin{aligned}
& A_{0}=\frac{\rho}{R}\left(\rho \int_{0}^{1} \Sigma_{R i}^{-1} d i+\rho \Pi \Sigma_{Z}^{-1} \Pi+\Pi\right)^{-1}\left(\int_{0}^{1} \Sigma_{R i}^{-1} d i \bar{R}+\Pi \Sigma_{Z}^{-1} \bar{Z}\right) \\
& A_{1}=\frac{1}{R}\left(\rho \int_{0}^{1} \Sigma_{R i}^{-1} d i+\rho \Pi \Sigma_{Z}^{-1} \Pi+\Pi\right)^{-1}\left(\Pi+\rho \Pi \Sigma_{Z}^{-1} \Pi\right) \\
& A_{2}=\frac{1}{R}\left(\rho \int_{0}^{1} \Sigma_{R i}^{-1} d i+\rho \Pi \Sigma_{Z}^{-1} \Pi+\Pi\right)^{-1}\left(I+\rho \Pi \Sigma_{Z}^{-1}\right)
\end{aligned}
$$

Following Admati, we defined $\Pi$ as the average precision matrix of the signals weighted by the risk tolerance coefficient.

$$
\Pi=\left[\int_{0}^{1} \rho C_{i}^{\prime} \Sigma_{i}^{-1} C_{i} d i\right]
$$

Intuitively, $\Pi$ contains the average stock market information processed by the investors. The conditional distribution of $\tilde{R}$ given a private signal $\tilde{Y}_{i}$ and the equilibrium price vector $\tilde{P}$ is a multivariate normal with variance-covariance matrix

$$
V_{i}=\operatorname{Var}\left[\tilde{R} \mid \tilde{Y}_{i}, \tilde{P}\right]=\left(\Sigma_{R i}^{-1}+\Pi \Sigma_{Z}^{-1} \Pi+C_{i}^{\prime} \Sigma_{i}^{-1} C_{i}\right)^{-1}
$$

The optimal asset holdings by an investor $i$, who observes the state of the world with a measurement error $\tilde{Y}_{i}$ and the equilibrium price vector $\tilde{P}$, are given by

$$
X_{i}\left(\tilde{Y}_{i}, \tilde{P}\right)=G_{0 i}+G_{1 i} \tilde{Y}_{i}-G_{2 i} \tilde{P}
$$

where

$$
\begin{aligned}
& G_{1 i}=\rho C_{i}^{\prime} \Sigma_{i}^{-1} \\
& G_{2 i}=\rho R\left[\begin{array}{c}
\left(\Sigma_{R i}^{-1}+\Pi \Sigma_{Z}^{-1} \Pi+C_{i}^{\prime} \Sigma_{i}^{-1} C_{i}\right)+ \\
-\Pi \Sigma_{Z}^{-1}\left(I+\rho \Pi \Sigma_{Z}^{-1}\right)^{-1}\left(\rho \int_{0}^{1} \Sigma_{R i}^{-1} d i+\rho \Pi \Sigma_{Z}^{-1} \Pi+\Pi\right)
\end{array}\right] \\
& G_{0 i}=\rho\left[\left(\Sigma_{R i}^{-1} \bar{R}+\Pi \Sigma_{Z}^{-1} \bar{Z}\right)-\rho \Pi \Sigma_{Z}^{-1}\left(I+\rho \Pi \Sigma_{Z}^{-1}\right)^{-1}\left(\int_{0}^{1} \Sigma_{R i}^{-1} d i \bar{R}+\Pi \Sigma_{Z}^{-1} \bar{Z}\right)\right]
\end{aligned}
$$

For a more detailed solution of the Proposition 1 see Admati (1985).

Proof of Proposition 2. First, rewrite the objective function. Then, proceed with the optimal attention allocation.

$$
E U_{i}=E\left[E\left[W_{i}^{\prime} \mid \tilde{Y}_{i}, \tilde{P}\right]-\frac{1}{2 \rho_{i}} \operatorname{Var}\left[W_{i}^{\prime} \mid \tilde{Y}_{i}, \tilde{P}\right]\right]
$$

where

$$
E\left[W_{i}^{\prime} \mid \tilde{Y}_{i}, \tilde{P}\right]=W_{i 0} R+\rho_{i}\left[E\left[\tilde{R} \mid \tilde{Y}_{i}, \tilde{P}\right]-R \tilde{P}\right]^{\prime} \operatorname{Var}\left[\tilde{R} \mid \tilde{Y}_{i}, \tilde{P}\right]^{-1}\left[E\left[\tilde{R} \mid \tilde{Y}_{i}, \tilde{P}\right]-R \tilde{P}\right]
$$


and

$$
\operatorname{Var}\left[W_{i}^{\prime} \mid \tilde{Y}_{i}, \tilde{P}\right]=\rho_{i}^{2}\left[E\left[\tilde{R} \mid \tilde{Y}_{i}, \tilde{P}\right]-R \tilde{P}\right]^{\prime} \operatorname{Var}\left[\tilde{R} \mid \tilde{Y}_{i}, \tilde{P}\right]^{-1}\left[E\left[\tilde{R}^{\prime} \tilde{Y}_{i}, \tilde{P}\right]-R \tilde{P}\right]
$$

The objective function becomes

$$
=E\left[\frac{1}{2} \rho_{i}\left[E\left[\tilde{R} \mid \tilde{Y}_{i}, \tilde{P}\right]-R \tilde{P}\right]^{\prime} V_{i}^{-1}\left[E\left[\tilde{R} \mid \tilde{Y}_{i}, \tilde{P}\right]-R \tilde{P}\right]+R W_{0, i}\right]
$$

Note that

$$
\begin{aligned}
E R & =E\left[E\left[\tilde{R} \mid \tilde{Y}_{i}, \tilde{P}\right]-R \tilde{P}\right]=\left(I-R A_{1}\right) \bar{R}-R A_{0}+R A_{2} \bar{Z} \\
& =\left(\rho \int_{0}^{1} \Sigma_{R i}^{-1} d i+\rho \Pi \Sigma_{Z}^{-1} \Pi+\Pi\right)^{-1} \bar{Z}
\end{aligned}
$$

where $E R=\left(e r_{h}, e r_{f}\right)^{\prime}$ and

$$
\begin{aligned}
Q_{i} & =\operatorname{Var}\left[E\left[\tilde{R} \mid \tilde{Y}_{i}, \tilde{P}\right]-R \tilde{P}\right]+V_{i}= \\
& =\Sigma_{R i}+R^{2} A_{1} \Sigma_{R i} A_{1}^{\prime}+R^{2} A_{2} \Sigma_{Z} A_{2}^{\prime}-R A_{1} \Sigma_{R i}-R \Sigma_{R i} A_{1}^{\prime}
\end{aligned}
$$

Let $x=\left(x_{1}, x_{2}, \ldots, x_{n}\right)^{\prime} \sim N(\mu, V)$. Define the quadratic form $q=x^{\prime} A x$, then the expected value of $q$ is $E(q)=\operatorname{tr}[A V]+\mu^{\prime} A \mu$. Therefore, the objective function is given by

$$
\rho_{i} \operatorname{Tr}\left(\frac{1}{2} V_{i}^{-1} Q_{i}\right)+\frac{1}{2} \rho_{i}\left[E\left[\tilde{R} \mid \tilde{Y}_{i}, \tilde{P}\right]-R \tilde{P}\right]^{\prime} V_{i}^{-1}\left[E\left[\tilde{R} \mid \tilde{Y}_{i}, \tilde{P}\right]-R \tilde{P}\right]+R W_{0, i}
$$

For any economy in which agents receive signals of the form $\tilde{Y}_{i}=C_{i} \tilde{R}+\tilde{\varepsilon}_{i}$, there exists an economy identical to the original in which investors receive private signals $\tilde{Y}_{i}^{*}=\mu \tilde{Y}_{i}=\mu C_{i} \tilde{R}+\mu \tilde{\varepsilon}_{i}$ that has an equilibrium which is indistinguishable from the equilibrium in the original economy and that satisfies the information capacity constraint as well. First, check that the equilibrium is indistinguishable between both economies. There is enough to prove that $\Pi=\Pi^{*}$

$$
\Pi=\int_{0}^{1} \rho_{i} C_{i}^{\prime} \Sigma_{i}^{-1} C_{i} d i=\int_{0}^{1} \rho_{i} \mu C_{i}^{\prime}\left(\mu^{2} \Sigma_{i}\right)^{-1} \mu C_{i} d i=\int_{0}^{1} \rho_{i} C_{i}^{* \prime}\left(\Sigma_{i}^{*}\right)^{-1} C_{i}^{*} d i=\Pi^{*}
$$

More details are provided in Admati (1985). Second, let's check that the new private signal satisfies the information capacity constraint. A nice property of Mutual Information is that it is invariant to any linear combination of the random variables, which implies

$$
I(X ; Y)=I(X ; \mu Y)=H(X)-H(X \mid Y) \leq \kappa
$$

Therefore, we need to introduce a constraint on $C_{i}$ in order to avoid the existence of indistinguishable equilibria. The relative weight of the linear combination in the private signal is what matters for the investor. We can normalize one element of each row vector of $C_{i}$. For any optimal linear combination of asset payoffs, $C_{i}^{*}$, which is

$$
C_{i}^{*}=\left(\begin{array}{cc}
1 & c_{f i} \\
c_{h i} & 1
\end{array}\right)
$$


let investors choose the optimal variance covariance matrix of the error in the private signal, $\Sigma_{i}$. The variance covariance matrix can be decomposed as follow

$$
\Sigma_{i}=P \Lambda P^{\prime}
$$

where $\Lambda$ is a diagonal matrix and $P^{\prime}=P^{-1}$. For every non-diagonal $\Sigma_{i}$, there exists an indistinguishable equilibrium where investors receive a private signal $\tilde{Y}_{i}^{*}$ given by

$$
\tilde{Y}_{i}^{*}=P^{-1} \tilde{Y}_{i}=P^{-1} C_{i} \tilde{R}+P^{-1} \tilde{\varepsilon}_{i}=C_{i}^{*} \tilde{R}+\tilde{\varepsilon}_{i}^{*}
$$

where $\operatorname{var}\left(\tilde{\varepsilon}_{i}^{*}\right)=\Lambda$ is a diagonal matrix. Therefore, without loss of generality for a given optimal matrix $C_{i}$, we can let investors choose a diagonal variance covariance matrix of the error term in the private signal

$$
\Sigma_{i}=\left(\begin{array}{cc}
\sigma_{i h} & 0 \\
0 & \sigma_{i f}
\end{array}\right)
$$

Agents maximize their objective function

$$
\begin{aligned}
& \max _{\substack{\sigma_{i h}^{-1}, \sigma_{i f}^{-1} \\
(}}\left(\left(e r_{h}^{2}+Q_{h h i}\right)+\left(e r_{f}^{2}+Q_{f f i}\right) c_{f i}^{2}+2\left(e r_{h} e r_{f}+Q_{h f i}\right) c_{f i}\right) \sigma_{i h}^{-1}+ \\
& +\left(\left(e r_{h}^{2}+Q_{h h i}\right) c_{h i}^{2}+\left(e r_{f}^{2}+Q_{f f i}\right)+2\left(e r_{h} e r_{f}+Q_{h f i}\right) c_{h i}\right) \sigma_{i f}^{-1}+\text { constant }
\end{aligned}
$$

subject to the information constraint

$$
\left(\frac{1}{\sigma_{r, i h}^{2}}+\frac{c_{f i}^{2}}{\sigma_{r, i f}^{2}}\right) \sigma_{i h}^{-1}+\left(\frac{1}{\sigma_{r, i f}^{2}}+\frac{c_{h i}^{2}}{\sigma_{r, i h}^{2}}\right) \sigma_{i f}^{-1}+\frac{\left(1-c_{h i} c_{f i}\right)^{2}}{\sigma_{r, i h}^{2} \sigma_{r, i f}^{2}} \sigma_{i h}^{-1} \sigma_{i f}^{-1}=\left(e^{2 \kappa}-1\right)
$$

where

$$
\begin{gathered}
e r_{h}=\frac{\left(\rho \bar{\alpha}+\pi_{f f}\right) \bar{z}_{h}-\left(\rho \gamma+\pi_{h f}\right) \bar{z}_{f}}{\left(\rho \bar{\beta}+\pi_{h h}\right)\left(\rho \bar{\alpha}+\pi_{f f}\right)-\left(\rho \gamma+\pi_{h f}\right)^{2}} \quad e r_{f}=\frac{\left(\rho \bar{\beta}+\pi_{h h}\right) \bar{z}_{f}-\left(\rho \gamma+\pi_{h f}\right) \bar{z}_{h}}{\left(\rho \bar{\beta}+\pi_{h h}\right)\left(\rho \bar{\alpha}+\pi_{f f}\right)-\left(\rho \gamma+\pi_{h f}\right)^{2}} \\
\alpha_{i}=\frac{1}{\sigma_{r, i f}^{2}}+\frac{\pi_{h f}^{2}}{\sigma_{z h}^{2}}+\frac{\pi_{f f}^{2}}{\sigma_{z f}^{2}} \quad \beta_{i}=\frac{1}{\sigma_{r, i h}^{2}}+\frac{\pi_{h h}^{2}}{\sigma_{z h}^{2}}+\frac{\pi_{h f}^{2}}{\sigma_{z f}^{2}} \quad \gamma=\frac{\pi_{h h} \pi_{h f}}{\sigma_{z h}^{2}}+\frac{\pi_{h f} \pi_{f f}}{\sigma_{z f}^{2}} \\
\bar{\alpha}=\lambda \alpha_{h}+(1-\lambda) \alpha_{f} \quad \bar{\beta}=\lambda \beta_{h}+(1-\lambda) \beta_{f} \\
\pi_{h h}=\int_{0}^{1} \rho \Sigma_{i}^{-1} d i \quad \pi_{h f}=\int_{0}^{1} \rho \Sigma_{i}^{-1} c_{f i} d i \quad \pi_{f f}=\int_{0}^{1} \rho \Sigma_{i}^{-1} c_{f i}^{2}
\end{gathered}
$$

The investor when optimizing takes as given $e r_{h}, e r_{f}, \alpha, \beta, \gamma, \pi_{h h}, \pi_{h f}$ and $\pi_{f f}$. Due to the linearity of the objective function in the precision of each private signal and the form of the information constraint, the maximum is a corner solution. Therefore, investors want to allocate all their attention in only one linear combination of asset payoffs.

Proof of Proposition 3. The objective function in the second period is given by

$$
\max _{C_{i}, \Sigma_{i}^{-1}} \operatorname{Tr}\left(V_{i}^{-1} Q_{i}\right)+E R^{\prime} V_{i}^{-1} E R
$$

subject to the information capacity constraint

$$
\ln |\operatorname{Var}(\tilde{R})|-\ln \left|\operatorname{Var}\left(\tilde{R} \mid \tilde{Y}_{i}\right)\right| \leq 2 \kappa
$$


which can be also written as

$$
\left|I+\Sigma_{R i}^{-1} C_{i}^{\prime} \Sigma_{i}^{-1} C_{i}\right| \leq \exp (2 \kappa)
$$

The precision of the error of the private signal can be obtained rearranging the information capacity constraint

$$
\Sigma_{i}^{-1}=\frac{\left(e^{2 \kappa}-1\right)}{\sigma_{r, i h}^{2}+c_{f i}^{2} \sigma_{r, i f}^{2}}
$$

Rearranging the terms in the objective function and introducing the precision of the private signal, investors maximize

$$
\max _{c_{f i}} \frac{\left[\left(e r_{h}^{2}+Q_{h h i}\right)+\left(e r_{f}^{2}+Q_{f f i}\right) c_{f i}^{2}+2\left(e r_{h} e r_{f}+Q_{h f i}\right) c_{f i}\right]\left(e^{2 \kappa}-1\right)}{\sigma_{r, i h}^{2}+c_{f i}^{2} \sigma_{r, i f}^{2}}
$$

where $Q_{h h i}, Q_{h f i}$ and $Q_{f f i}$ are given by (7) and $e r_{h}$ and $e r_{f}$ are given in (8). The denominator is always positive. The objective function is continuous since the numerator and denominator are polynomials and the denominator never equals zero. The investor when optimizing takes as given $e r_{h}, e r_{f}, Q_{h h i}, Q_{h f i}$ and $Q_{f f i}$. Since the investor has an infinitesimal measure, her decision does not have any effect on the price. The First Order Condition is given by

$$
\begin{gathered}
{\left[-\sigma_{r, i f}^{2}\left(e r_{h} e r_{f}+Q_{h f i}\right) c_{f i}^{2}+\left(\sigma_{r, i h}^{2}\left(e r_{f}^{2}+Q_{f f i}\right)-\sigma_{r, i f}^{2}\left(e r_{h}^{2}+Q_{h h i}\right)\right) c_{f i}+\right.} \\
\left.+\sigma_{r, i h}^{2}\left(e r_{h} e r_{f}+Q_{h f i}\right)\right] \frac{2}{\left(\sigma_{r, i h}^{2}+c_{f i}^{2} \sigma_{r, i f}^{2}\right)^{2}}=0
\end{gathered}
$$

Note that the first derivative of the objective function is also a continuous function. The optimal $c_{f i}$ is found by solving the quadratic equation of the FOC. There are two solutions to the FOC

$$
c_{f i}^{+}=\frac{\left[\sigma_{r, i h}^{2}\left(e r_{f}^{2}+Q_{f f i}\right)-\sigma_{r, i f}^{2}\left(e r_{h}^{2}+Q_{h h i}\right)\right]+\sqrt{\left[\sigma_{r, i h}^{2}\left(e r_{f}^{2}+Q_{f f i}\right)-\sigma_{r, i f}^{2}\left(e r_{h}^{2}+Q_{h h i}\right)\right]^{2}+4 \sigma_{r, i h}^{2} \sigma_{r, i f}^{2}\left(e r_{h} e r_{f}+Q_{h f i}\right)^{2}}}{2\left[\sigma_{r, i f}^{2}\left(e r_{h} e r_{f}+Q_{h f i}\right)\right]}
$$

This is the reaction function where investors take as given the aggregate variables of the economy. $c_{f i}^{+}$ is always a unique maximum since the second order condition is always negative at this point

$$
-2 \sigma_{r, i f}^{2}\left(e r_{h} e r_{f}+Q_{h f i}\right) c_{f i}^{+}+\left[\sigma_{r, i h}^{2}\left(e r_{f}^{2}+Q_{f f i}\right)-\sigma_{r, i f}^{2}\left(e r_{h}^{2}+Q_{h h i}\right)\right]<0
$$

The other solution to the $F O C$ is given by

$$
c_{f i}^{-}=\frac{\left[\sigma_{r, i h}^{2}\left(e r_{f}^{2}+Q_{f f i}\right)-\sigma_{r, i f}^{2}\left(e r_{h}^{2}+Q_{h h i}\right)\right]-\sqrt{\left[\sigma_{r, i h}^{2}\left(e r_{f}^{2}+Q_{f f i}\right)-\sigma_{r, i f}^{2}\left(e r_{h}^{2}+Q_{h h i}\right)\right]^{2}+4 \sigma_{r, i h}^{2} \sigma_{r, i f}^{2}\left(e r_{h} e r_{f}+Q_{h f i}\right)^{2}}}{2\left[\sigma_{r, i f}^{2}\left(e r_{h} e r_{f}+Q_{h f i}\right)\right]}
$$

which is always a minimum since the second order condition is always positive at this point

$$
-2 \sigma_{r, i f}^{2}\left(e r_{h} e r_{f}+Q_{h f i}\right) c_{f i}^{-}+\left[\sigma_{r, i h}^{2}\left(e r_{f}^{2}+Q_{f f i}\right)-\sigma_{r, i f}^{2}\left(e r_{h}^{2}+Q_{h h i}\right)\right]>0
$$

An equilibrium is given by the optimal $c_{f i}$ which is consistent with all investors choosing the same $c_{f i}$. By substituting the values of $e r_{h}, e r_{f}, Q_{h h i}, Q_{h f i}$ and $Q_{f f i}$ into the $F O C$ and imposing that all 
investors choose the same $c_{f i}$, we obtain the following expression

$\left[-\sigma_{r f}^{2} \bar{z}_{h} \bar{z}_{f} c_{f}^{2}+\left(\sigma_{r f}^{2} \sigma_{z f}^{2}+\sigma_{r f}^{2} \bar{z}_{f}^{2}-\sigma_{r h}^{2} \sigma_{z h}^{2}-\sigma_{r h}^{2} \bar{z}_{h}^{2}\right) c_{f}+\sigma_{r h}^{2} \bar{z}_{h} \bar{z}_{f}\right] \times[$ Strictly positive term $]=0$

The optimal solution for $c_{f}$ is

$c_{f}^{*}=\frac{\left(\sigma_{r f}^{2} \sigma_{z f}^{2}+\sigma_{r f}^{2} \bar{z}_{f}^{2}-\sigma_{r h}^{2} \sigma_{z h}^{2}-\sigma_{r h}^{2} \bar{z}_{h}^{2}\right)+\sqrt{\left(\sigma_{r f}^{2} \sigma_{z f}^{2}+\sigma_{r f}^{2} \bar{z}_{f}^{2}-\sigma_{r h}^{2} \sigma_{z h}^{2}-\sigma_{r h}^{2} \bar{z}_{h}^{2}\right)^{2}+4 \sigma_{r h}^{2} \sigma_{r f}^{2} \bar{z}_{h}^{2} \bar{z}_{f}^{2}}}{2 \sigma_{r f}^{2} \bar{z}_{h} \bar{z}_{f}}$

The SOC under $c_{f}^{*}$

$$
\left[-2 \sigma_{r f}^{2} \bar{z}_{h} \bar{z}_{f} c_{f}^{*}+\left(\sigma_{r f}^{2} \sigma_{z f}^{2}+\sigma_{r f}^{2} \bar{z}_{f}^{2}-\sigma_{r h}^{2} \sigma_{z h}^{2}-\sigma_{r h}^{2} \bar{z}_{h}^{2}\right)\right] \times[\text { Strictly positive term }]<0
$$

The optimal $c_{f}^{*}$ is always positive. Therefore, there is sufficient and necessary conditions in order to have an equilibrium

$$
\left(e r_{h} e r_{f}+Q_{h f i}\right)>0
$$

which can be rewritten as

$$
Q_{h f i}>-\bar{Q}=-e r_{h} e r_{f}
$$

The optimal precision of the error term in the private signal is given by equation (12). Furthermore, both equilibria satisfy the "no-forgetting constraint", which is

$$
\operatorname{Var}(\tilde{R})-\operatorname{Var}\left(\tilde{R} \mid \tilde{Y}_{i}\right) \text { positive semi-definite }
$$

\section{B Autocorrelation of Asset Payoffs}

We collected data between Jan 1st, 1980 and Dec 31, 2004 on three major stock price indexes in U.S.: the Dow Jones Industrial Average Index, the NYSE Composite Index, and the S\&P 500. The original data is at the daily frequency, and for each of the stock price index we calculate two annual series.

\begin{tabular}{|c|c|c|}
\hline \multirow[b]{2}{*}{ Stock Market Index } & \multicolumn{2}{|c|}{ Autocorrelations } \\
\hline & end-of-period & average \\
\hline Dow Jones (U.S.) & 0.905 & 0.910 \\
\hline NYSE (U.S.) & 0.879 & 0.885 \\
\hline S\&P (U.S.) & 0.895 & 0.901 \\
\hline
\end{tabular}
The end-of-period series contains the closing stock index price at the last trading day of the year; the average series contain the yearly average of the daily closing stock index prices.

Table 8: First Order Autocorrelation of U.S. Stock Market Indices

Table (8) presents the first-order autocorrelations of the end-of-period and average annual indexes. We can see that the autocorrelations range from 0.88 to 0.91 . 